\title{
Co-production of Hydrogen and Electricity from Lignocellulosic Biomass: Process Design and Thermo-economic Optimization
}

\author{
Laurence Tock ${ }^{\mathrm{a}}$, François Maréchal ${ }^{\mathrm{a}}$ \\ ${ }^{a}$ Laboratory for Industrial Energy Systems, Ecole Polytechnique Fédérale de Lausanne \\ $\mathrm{CH}-1015$ Lausanne, Switzerland
}

Energy 2012 doi:10.1016/j.energy.2012.01.056

\begin{abstract}
The thermochemical production of hydrogen from lignocellulosic biomass is systematically analyzed by developing thermo-environomic models combining thermodynamics with economic analysis, process integration techniques and optimization strategies for the conceptual process design. $\mathrm{H}_{2}$ is produced by biomass gasification and subsequent gas treatment, followed by $\mathrm{H}_{2}$ purification via $\mathrm{CO}_{2}$ removal. It is shown how the overall efficiency is improved by considering process integration and computing the optimal integration of combined heat and power production. In the conversion process, electricity can be generated in steam and gas turbine cycles using the combustion of the off-gases and recovering available process heat. Additional electricity can be produced by burning part of the $\mathrm{H}_{2}$-rich intermediate or of the purified $\mathrm{H}_{2}$ product. The trade-off between $\mathrm{H}_{2}$ and electricity co-production and $\mathrm{H}_{2}$ or electricity only generation is assessed with regard to energy, economic and environmental considerations. Based on multi-objective optimization, the most promising options for the poly-generation of hydrogen, power and heat are identified with regard to different process configurations. The best compromise between efficiency, $\mathrm{H}_{2}$ and/or electricity production cost and $\mathrm{CO}_{2}$ capture is identified. Biomass based $\mathrm{H}_{2}$ and electricity reveal to be a competitive alternative in a future sustainable energy system.
\end{abstract}

Keywords:Biomass, Hydrogen, Polygeneration, Process integration, Thermo-economic optimization, Life cycle assessment

\section{Nomenclature}

\author{
Abbreviations \\ BM Biomass \\ CC Carbon Capture \\ CFB Circulating Fluidized Bed \\ CGC Cold Gas Cleaning \\ COE Cost Of Electricity \\ $\mathrm{E}_{i m p}$ Electricity import \\ FICFB Fast Internally Circulating Fluidized Bed \\ GT Gas Turbine \\ GWP Global Warming Potential \\ HHV Higher Heating Value \\ HP Heat Pump \\ HTS High Temperature Shift
}

IBGCC Integrated Biomass Gasification Combined Cycle 
IGCC Integrated Gasification Combined Cycle

IPCC Intergovernmental Panel on Climate Change

LCA Life Cycle Assessment

LCI Life Cycle Inventory

LHV Lower Heating Value

LTS Low Temperature Shift

MDEA Methyldiethanolamine

MEA Monoethanolamine

MOO Multi-Objective Optimization

NG Natural Gas

NGCC Natural Gas Combined Cycle

PC Pulverized Coal

PG Producer Gas

PM Particulate Matter

PSA Pressure Swing Adsorption

RME Rape Methyl Ester

SMR Steam Methane Reforming

WGS Water-Gas Shift

Greek letters

$\Delta h^{o} \quad$ Lower heating value, $\mathrm{kJ} / \mathrm{kg}$

$\Delta \tilde{h}_{r}{ }^{0} \quad$ Standard heat of reaction, $\mathrm{kJ} / \mathrm{mol}$

$\Delta k^{o} \quad$ Exergy value, $\mathrm{kJ} / \mathrm{kg}$

$\epsilon_{e q} \quad$ Natural gas equivalent efficiency, \%

$\epsilon_{\mathrm{H} 2} \quad \mathrm{H}_{2}$ efficiency, \%

$\epsilon_{e x} \quad$ Exergy efficiency, \%

$\epsilon_{t o t} \quad$ Energy efficiency, $\%$

$\eta \quad$ Efficiency, \%

$\eta_{\mathrm{CO} 2} \quad \mathrm{CO}_{2}$ capture rate, $\%$

$\theta_{\text {wood }}$ Wood humidity, \%wt

$Y_{H 2} \quad \mathrm{H}_{2}$ Yield, $\mathrm{g}_{H 2} / \mathrm{kg}_{B M}$

Roman letters

$\dot{E} \quad$ Mechanical/electrical power, $\mathrm{kW}$

$\dot{m} \quad$ Mass flow, $\mathrm{kg} / \mathrm{s}$

$P \quad$ Pressure, bar

$\dot{Q} \quad$ Heat, $\mathrm{kW}$

$T \quad$ Temperature, ${ }^{\circ} \mathrm{C}$ or $\mathrm{K}$

\section{Superscripts}

$+\quad$ Material/energy stream entering the system

- Material/energy stream leaving the system

\section{Introduction}

In a future clean and abundant energy system, hydrogen is to be considered as an alternative energy carrier. $\mathrm{H}_{2}$ is a clean fuel that can be used in combustion engines and fuel cells for electricity generation without local $\mathrm{CO}_{2}$ emissions. Being a secondary form of energy, $\mathrm{H}_{2}$ does not freely exist in nature and consequently has to be manufactured. Today $\mathrm{H}_{2}$ is produced essentially by steam methane reforming, coal gasification and in a lesser extent by water electrolysis $[2,3,10]$. The drawback of these processes is that they are using fossil fuels or electricity from non-renewable sources. Within the worldwide challenge of global warming mitigation and energy supply, alternative $\mathrm{H}_{2}$ production processes from renewable resources have received considerable attention. Different renewable energy resources may be used like wind, biomass or solar energy 
$[2,10]$. Biomass-based technologies have a high potential because they emit no or very few net $\mathrm{CO}_{2}$ emissions, if carefully managed, since the released $\mathrm{CO}_{2}$ was previously fixed in the plant as hydrocarbon by photosynthesis. $\mathrm{H}_{2}$ production from biomass can be divided into two categories; thermo-chemical processes (i.e. biomass gasification and pyrolysis) and biological processes (i.e. biophotolysis and fermentation). An overview of these $\mathrm{H}_{2}$ production processes from fossil and renewable resources and its economics can be found in [3].

The economic surveys in $[3,28,18]$ among with other studies assessing the energy and exergy efficiency of the biomass conversion into $\mathrm{H}_{2}$, as well as the influence of operating conditions, show that it is a technical feasible process that could be promising on the future energy market $[16,30,29,7,1,33,36] . \mathrm{H}_{2}$ yields in the range of $80-130 \mathrm{~g}_{\mathrm{H} 2} / \mathrm{kg}_{\text {Biomass }}$ are assessed in $[1,33]$. Energy efficiencies between 51 and $60 \%$ on lower heating value basis and $\mathrm{H}_{2}$ production cost ranging from 29 to over $40 \$ / \mathrm{MWh}_{H 2}$ are reported for biomass based $\mathrm{H}_{2}$ processes in [16]. The performance of some $\mathrm{H}_{2}$ processes using fossil or renewable resources are compared in Table 1.

Instead of producing $\mathrm{H}_{2}$ from biomass, electricity can be generated in an integrated biomass gasification combined cycle (IBGCC) $[6,21,8,19,5]$. Even if there are still some technological challenges, this option appears as promising for $\mathrm{CO}_{2}$ mitigation when compared to fossil fuel based power plants with $\mathrm{CO}_{2}$ capture as shown by the performances reported in Table 2. Carbon capture decreases the efficiency of fossil power plants by around $10 \%$ points and increases the electricity cost by nearly one third which yields $\mathrm{CO}_{2}$ avoidance cost in the range of $13-75 \$ / \mathrm{t}$ $\mathrm{CO}_{2, \text { avoided }}$ [24]. Polygeneration processes co-producing $\mathrm{H}_{2}$ and electricity can also be considered as an alternative.

The different studies about biomass conversion into $\mathrm{H}_{2}$ or electricity assessed the process performance either by the thermal efficiency [7, 5], the economics $[30,8]$ or by the life cycle impacts $[6,21]$. In some of these researches performance analyses and cost or environmental assessment are combined. However, no consistent comparison and optimization considering efficiency, costs and environmental impacts at the same time is performed. The difficulty to choose the best concept without including these three dimensions is revealed in [20] making a comparison of natural gas power plants concepts with $\mathrm{CO}_{2}$ capture based on efficiency and $\mathrm{CO}_{2}$ emissions without including economics. Moreover, in these studies energy integration is most of the time not explicitly considered. This may lead to sub-optimal solutions from the energy efficiency point of view. In $[11,26]$ the advantage of applying energy integration in biomass conversion processes is demonstrated. Environmental objectives have been introduced in a multiobjective optimization strategy combining energy integration and life cycle assessment (LCA) in [4] to study the impact of $\mathrm{CO}_{2}$ capture in NGCC plants. This approach was also successfully applied to reveal potential process improvements in biomass conversion into synthetic natural gas [15] but has not yet been applied for $\mathrm{H}_{2}$ and power generation.

In this paper, the thermochemical conversion of biomass into $\mathrm{H}_{2}$ and electricity is investigated and optimized with regard to energy, economic and environmental considerations. This is done by applying a consistent methodology $[15,12,31]$ combining thermodynamics with economic analysis, process integration techniques and using optimization strategies to generate optimal process configurations. The objective is to assess the competition between hydrogen or electricity only production processes and polygeneration with and without $\mathrm{CO}_{2}$ capture by studying the influence of the operating conditions and process configurations. The use of process integration techniques allows to focus on the heat recovery and the energy conversion performance and on polygeneration aspects of $\mathrm{H}_{2}$, heat and power and captured $\mathrm{CO}_{2}$.

\section{Methodology}

This paper follows a previously developed methodology for the optimal thermo-economic process design of liquid and gaseous fuel production from biomass [15, 12, 31, 13]. The conceptual design methodology is illustrated in Figure 1. First suitable process technologies are identified 
and thermo-economic models of the process units are developed. The thermodynamic model computes the chemical and physical transformations and the associated heat transfer requirements. It is combined with a separate energy integration model representing the heat recovery system. Based on the pinch analysis methodology, the optimal thermal process integration is computed after defining the maximum heat recovery potential between hot and cold streams and considering a minimum approach temperature $\Delta T_{m i n}$. The process needs are satisfied by different utilities such as, combustion of waste and producer gas (PG), steam Rankine cycle for power production, gas turbine and cogeneration by burning either $\mathrm{H}_{2}$-rich fuel or almost pure $\mathrm{H}_{2}$. The optimal utility integration is defined by maximizing the combined production of fuel, power and heat with regard to the minimal operating cost by solving a linear programming problem $[12,22,23]$. Using the data from the flowsheeting and process integration models, the costs are estimated based on equipment sizing and cost correlations from the literature [34, 35]. For the life cycle inventory model, the cradle-to-gate LCA approach described in [15] is applied with a functional unit of $1 \mathrm{~kJ}$ of biomass at the inlet of the installation. The impact assessment method developed by the Intergovernmental Panel on Climate Change (IPCC) considering a time horizon of 100 years for the global warming potential (GWP) is used as the environmental performance indicator. Finally a multi-objective optimization using an evolutionary algorithm $[12,25]$ is performed. The optimization allows to identify competing objectives with regard to environomic (i.e. thermodynamic, economic and environmental) criteria and to assess the different trade-offs. The main feature of this methodology is the use of flowsheeting and process integration models in a multi-objective optimization framework that takes into account simultaneously economic and environmental considerations. In conventional process evaluation approaches, the processes are first designed and then different process configurations are compared based on various criteria. In comparison with conventional methods where process configuration scenario are compared, the proposed method allows one to make a systematic generation of optimal process configurations and to compare these on the same consistent performance criteria.

\section{Process description}

The thermochemical process converting biomass into $\mathrm{H}_{2}$ fuel consists of wood handling, drying, gasification, gas cleaning and conditioning by reforming and shift conversion, and finally $\mathrm{H}_{2} \mathrm{pu}-$ rification and/or $\mathrm{H}_{2}$ burning for electricity generation. For each process step, several technology options can be proposed. This results into a process superstructure that is presented in Figure 2 , where the investigated process layouts and the life cycle inventory (LCI) flows within the system's limits are highlighted. A separate torrefaction step is introduced before the gasification step to take advantage of the heat integration. The torrefaction operating at around $530[\mathrm{~K}]$ shifts part of the high temperature heat required for gasification to lower temperatures and yields torrified gas which can be used for heat and power generation; leading to higher process performances. The products (i.e. $\mathrm{H}_{2}$ or electricity) are defined by the options chosen at the cross points A and B. Depending on the production purpose and on the fuel which is burnt, the process either produces impure $(80 \% \mathrm{~mol})$ or pure $\mathrm{H}_{2}(99 \% \mathrm{~mol})$, imports or exports electricity, or is self-sufficient in terms of electricity.

\subsection{Thermo-economic process model}

The thermo-economic models for the drying, gasification and gas cleaning section have been developed in previous work $[31,13,14]$ and the same specifications for the biomass and process units are considered in this work. The chemical conversion in the gasifier is modeled by equilibrium relationships with an artificial temperature difference as explained in $[13,14]$. After the gasification the syngas is treated in two sequential water gas shift (WGS) reactors (Eq.1) one (HTS) operating at high [573-683K] and one (LTS) at lower [473-573K] temperature. This 
increases the $\mathrm{H}_{2}$ and $\mathrm{CO}_{2}$ concentrations before $\mathrm{CO}_{2}$ removal reducing the greenhouse gas emissions and producing higher LHV fuel.

$$
\mathrm{CO}+\mathrm{H}_{2} \mathrm{O} \quad \stackrel{\Delta \tilde{h}_{r}{ }^{0}=-41}{\leftrightarrow} \mathrm{kJ} / \mathrm{mol} \quad \mathrm{CO}_{2}+\mathrm{H}_{2}
$$

For the $\mathrm{H}_{2}$ separation and purification, $\mathrm{CO}_{2}$ capture by chemical absorption with amines and by physical adsorption using pressure swing adsorption (PSA) are considered. A chemical absorption step is introduced before the PSA unit to produce pure $\mathrm{H}_{2}$ and to capture high purity $\mathrm{CO}_{2}$ which is compressed to over 100 [bar] for storage. For separating high partial pressure $\mathrm{CO}_{2}$ from syngas methyldiethanolamine (MDEA) is commonly used, while for low partial pressure $\mathrm{CO}_{2}$ (flue gas) monoethanolamine (MEA) is used. Here the chemical absorption with amines is modeled as a blackbox considering the average energy demands for the separation given in [27] and summarized in Table 3. In order to account for the influence of the solvent on the efficiency and cost, a more detailed model would be required, which was considered out of the scope of this study. In [32] a more sophisticated methodology for developing energy and cost correlations of $\mathrm{CO}_{2}$ capture processes is proposed. For the PSA model, the approach outlined in [13] is adapted for $\mathrm{H}_{2} / \mathrm{CO}_{2}$ separation based on data from [17]. PSA yields $\mathrm{H}_{2}$ purities of over $99 \% \mathrm{~mol}$. The nominal operating conditions of the main process units, as well as their ranges are summarized in Table 4.

\section{Process performance}

\subsection{Performance indicators}

The first law energy efficiency $\epsilon_{\text {tot }}$ defined by Eq.2 characterizes the chemical conversion and the quality of the process integration by taking into account the energy of the products and resources. In this definition thermal and mechanical energy are considered as being equivalent, however with regard to energy quality they are not equal. Therefore, the natural gas (NG) equivalent efficiency $\epsilon_{e q}$ (Eq. 3) is introduced to compare the value of the products with respect to the technical feasibility of their further conversion into final energy services. In $\epsilon_{e q}$, the net electricity that is consumed is substituted by a NG equivalent calculated based on an energy efficiency of $55 \%$. The $\mathrm{H}_{2}$ productivity is defined by the $\mathrm{H}_{2}$ yield $\mathrm{Y}_{H_{2}}$ (Eq.5). The conversion efficiency $\epsilon_{H 2}$ (Eq.6) expresses the production of the $\mathrm{H}_{2}$ fuel with regard to the biomass resource consumption, without taking into account the electricity import or export. The $\mathrm{CO}_{2}$ capture rate is given by the molar ratio between the captured carbon and the carbon entering the system (Eq.7). The exergy efficiency $\epsilon_{e x}$ (Eq.4) is also computed with $\Delta k_{d r y, \text { Biomass }}^{o}=20.9 \mathrm{MJ} / \mathrm{kg}$. All the reported efficiencies are expressed on the basis of the lower heating value $\left(\Delta h^{0}\right.$, LHV) of dry biomass. 


$$
\begin{aligned}
& \epsilon_{\text {tot }}=\frac{\Delta h_{\text {fuel,out }}^{0} \cdot \dot{m}_{\text {fuel }, \text { out }}+\dot{E}^{-}}{\Delta h_{\text {Biomass }, \text { in }}^{0} \cdot \dot{m}_{\text {Biomass }, \text { in }}+\dot{E}^{+}} \\
& \epsilon_{e q}=\frac{\Delta h_{\text {Fuel,out }}^{0} \cdot \dot{m}_{\text {Fuel,out }}+\frac{1}{\eta_{N G C C}} \frac{\Delta h_{N G}^{0}}{\Delta k_{N G}^{o}}\left(\frac{1}{\eta_{H P}} \dot{Q}^{-}+\dot{E}^{-}\right)}{\Delta h_{\text {Biomass }, \text { in }}^{0} \cdot \dot{m}_{\text {Biomass }, \text { in }}} \\
& \epsilon_{\text {ex }}=\frac{\Delta k_{\text {fuel }, \text { out }} \cdot \dot{m}_{\text {fuel,out }}+\dot{E}^{-}}{\Delta k_{\text {Biomass }, \text { in }} \cdot \dot{m}_{\text {Biomass }, \text { in }}+\dot{E}^{+}} \\
& Y_{H 2}=\frac{g_{H_{2}}}{k g_{\text {biomass }}} \\
& \epsilon_{H 2}=\frac{\Delta h_{H 2 \text { fuel }}^{0} \cdot \dot{m}_{H 2 \text { fuel }}}{\Delta h_{\text {Biomass }, \text { in }}^{0} \cdot \dot{m}_{\text {Biomass }, \text { in }}} \\
& \eta_{C O 2}=\frac{\text { molC }_{\text {captured }}}{\text { molC }_{\text {in }}} \cdot 100
\end{aligned}
$$

The economic performance is defined by the capital investment and the operating cost estimated according to $[34,35]$ with the assumptions given in Table 5 . All the performance analyses are performed for a plant capacity of $380 \mathrm{MW}_{\text {th,biomass }}$ of dry biomass.

\subsection{Energy integration}

Heat integration and recovery are important with regard to the process performance since several parts of the system operate at high temperature. The minimum energy requirement is computed from the hot and cold process streams through the heat cascade method accounting for the potential heat recovery. Heat is required by the gasification, the endothermic reforming, the water evaporation for gasification and the $\mathrm{CO}_{2}$ capture. The exothermic WGS and the process and offgas cooling release heat. The heat demands can be satisfied by different utilities. High temperature heat is delivered by the combustion of waste streams (i.e. unconverted char and gaseous residues of the separation and purification sections) and if necessary additional process streams (i.e. hot or cold syngas from the gasifier) and depending on the production scope also by the burning of $\mathrm{H}_{2}$-rich gas or pure $\mathrm{H}_{2}$ in a gas turbine to co-produce electricity. In general, the best choice is determined by assembling the potential fuels in a superstructure, integrating the different possibilities and computing the optimal solution by minimizing the operating cost using a linear programming model [23]. In the linear programming problem a cost is attributed to the electricity import/export (i.e. [50-270\$/MWh]) and to the $\mathrm{CO}_{2}$ emissions (i.e. $36 \$ /$ to $_{\mathrm{CO} 2}$, $\left[15-90 \$ /\right.$ to $\left.\left._{\mathrm{CO}}\right]\right)$. Surplus heat can be recovered in a Rankine cycle with an extraction steam turbine/generator to generate additional electricity and supply steam for gasification, steam methane reforming and shift conversion. A cycle with two production, two usage and one condensation level is considered and adapted to the different process configurations with regard to the parameters given in Table 6 . The remaining excess heat is removed by cooling water. The process integration including hot and cold utilities for two different configurations (Table 7:A\&B) producing $\mathrm{H}_{2}$ is represented in Figure 3 and discussed in detail in Section 4.3.

\subsection{Process integration analysis}

The influence of the heat recovery and the cogeneration systems including the introduction of a steam network, gas turbines (GT) or heat pumps (HP) is analyzed with regard to $\mathrm{H}_{2}$ and electricity production and captured $\mathrm{CO}_{2}$. Table 7 summarizes the different process configurations and the computed performances. 


\subsection{1 $\mathrm{H}_{2}$ production processes}

For the process configurations producing $\mathrm{H}_{2}$ by biomass conversion, different options with $\mathrm{H}_{2}$ purification and/or carbon capture are considered. The performances are reported as configurations A-F in Table 7. The energy integration of the process with $\mathrm{H}_{2}$ separation by PSA and without or with carbon capture by chemical absorption with amines is illustrated in Figure 3. Since the pinch point is located at low temperature, there is no excess heat that can be used in a Rankine cycle. By introducing a heat pump, excess heat from below the pinch can be transfered to a higher temperature for valorization in a Rankine cycle and consequently the energy integration of the $\mathrm{CO}_{2}$ capture is improved as shown in Figure 4 (Table 7:C).

The influence of $\mathrm{CO}_{2}$ capture is studied by the comparison of configurations $\mathrm{B}$ and $\mathrm{C}$ (Table 7). $\mathrm{CO}_{2}$ capture increases the power consumption considerably due to the energy requirement for the solvent regeneration and the $\mathrm{CO}_{2}$ compression. The purchase of the capture unit equipments increases the capital investment and consequently the production cost are increased by around one third. Through $\mathrm{H}_{2}$ purification, the $\mathrm{H}_{2}$ yield is increased by over $10 \%$ and the environmental impact is decreased because of the $\mathrm{CO}_{2}$ storage. By performing a multi-objective optimization, it is shown in Section 4.4 how the performance can be improved further to reach an overall energy efficiency around $60 \%$ with $\mathrm{CO}_{2}$ capture (Table $7: \mathrm{C}_{\text {opt }}$ ) by changing the operating conditions.

For these configurations electricity is imported to satisfy the overall process demands. Alternatively, part of the $\mathrm{H}_{2}$ rich gas and/or $\mathrm{H}_{2}$ product can be burnt in a gas turbine to cover the power demand and yield a self-sufficient process in terms of heat and power (Table 7:D). The energy integration of such a configuration is represented in Figure 5. The self-sufficient $\mathrm{H}_{2}$ process has a lower $\mathrm{H}_{2}$ yield, since part of the product is used for electricity production which leads to an energy efficiency decrease of more than $10 \%$ points. The equivalent efficiency $\epsilon_{e q}$ is however increased by around $10 \%$ points which shows that the integrated electricity production is more efficient than a NGCC plant. Due to the reduced electricity cost, the production cost are slightly reduced, even if the $\mathrm{H}_{2}$ yield is reduced and the capital investment increased. However, for keeping a higher level of $\mathrm{CO}_{2}$ capture in the process, the production cost would be larger (Table 8). In Sections 4.4\&4.5, it is shown that the process can become more attractive by changing the operating conditions and that the economic competitiveness of this option depends highly on the electricity and fuel market prices and the $\mathrm{CO}_{2}$ taxes.

The $\mathrm{H}_{2}$ purification by PSA (Table 7:C) increases the $\mathrm{H}_{2}$ purity by around $2.5 \%$ compared to the process without PSA (Table 7:E). The electricity demand and the investment are increased, however the overall impact on the performance is relatively low since the $\mathrm{H}_{2}$ yield is increased.

\subsubsection{Electricity only production processes}

Instead of generating $\mathrm{H}_{2}$ as a final product, electricity can also by produced by burning the $\mathrm{H}_{2}$ gas products in a gas turbine combined cycle. Different configurations producing electricity as a final product are assessed (Table 7:G-J): electricity generation from nearly pure $\mathrm{H}_{2}$ and electricity generation by the combustion of the $\mathrm{H}_{2}$-rich stream after WGS without (config. G\&I) and with carbon capture (config. $\mathrm{H} \& \mathrm{~J}$ ). $\mathrm{H}_{2}$ purification and carbon capture adding additional cost, the configuration burning impure $\mathrm{H}_{2}$ (lower LHV fuel) without $\mathrm{CO}_{2}$ capture (config. I) yields the lowest investment cost. Burning pure $\mathrm{H}_{2}$ (higher LHV fuel) generates more electricity in the gas turbine which outweighs the additional power consumption for $\mathrm{H}_{2}$ purification and consequently yields a higher energy efficiency. However, there are still some concerns with regard to flame stability which have to be addressed for high purity $\mathrm{H}_{2}$ combustion. $\mathrm{CO}_{2}$ capture leads to a negative $\mathrm{CO}_{2}$ balance for biomass based processes. It reduces the efficiency by around $10 \%$ and increases the production cost considerably. The difference in the energy integration for the electricity generation without and with $\mathrm{CO}_{2}$ capture is reported in Figure $6 \& 7$ respectively. In these configurations, the energy demand is satisfied by the heat generated from the gas turbine and by the combustion of waste streams. The computed efficiencies are in the range of the 
IBGCC power plant efficiency with and without $\mathrm{CO}_{2}$ reported in $[6,8,19]$. In [19] efficiencies in the range of $37-44 \%$ are reported and in [6] an efficiency of $33.9 \%$ is assessed with $\mathrm{CO}_{2}$ capture.

\subsection{Process optimization}

To investigate the trade-off between several competing factors defining the process performance, multi-objective optimization is performed by applying an evolutionary algorithm. The decision variables and their variation range are given in Tables 4 and 6 for the $\mathrm{H}_{2}$ process and the steam network, respectively. The advantage of using an evolutionary algorithm like the one described in [25], is that it allows to generate the Pareto set, even if some of the simulated points do not converge and if the problem is non-differentiable.

Four scenarios are optimized: $\mathrm{H}_{2}$ production with electricity import (config. C), self-sufficient $\mathrm{H}_{2}$ production (config. D), electricity generation from nearly pure $\mathrm{H}_{2}$ (config. $\mathrm{H}$ ) and electricity generation from $\mathrm{H}_{2}$-rich gas (config. J). First, the maximization of the energy efficiency $\epsilon_{\text {tot }}$ and the minimization of the capital investment are chosen as objectives. The objective functions are obtained by solving the thermo-economic model described in section 3.1 for each set of decision variables. The heuristics embeded in the sizing and cost estimation model guarantee that industrial infeasible solutions are avoided. The optimal Pareto frontiers are presented in Figure 8. The energy efficiency increase is correlated with the investment increase. For each scenario, the performance of one optimal configuration yielding a high $\epsilon_{t o t}$ is reported in Table 7 $\left(\mathrm{C}_{\text {opt }} / \mathrm{D}_{\text {opt }} / \mathrm{H}_{\text {opt }} / \mathrm{J}_{\text {opt }}\right)$. The energy integration and the main operating conditions of the optimal $\mathrm{H}_{2}$ process designs are represented in Figure 10\&11, respectively. Looking at the equivalent efficiency instead of $\epsilon_{t o t}$, the self-sufficient scenario $\left(\mathrm{D}_{\text {opt }}\right)$ performs better than the one with electricity import $\left(\mathrm{C}_{\text {opt }}\right)$. The optimization leads to better energy efficiency and lower cost when compared to the base case configurations. However, the $\mathrm{CO}_{2}$ capture rate is lower and consequently the environmental benefit is less important. The trade-off between the energy efficiency and the $\mathrm{CO}_{2}$ capture rate is highlighted by the optimal Pareto frontier resulting from the maximization of the energy efficiency and the $\mathrm{CO}_{2}$ capture rate as reported in Figure 9 . With regard to competitiveness, a compromise between the different objectives has to be found. The performance of selected optimal configurations yielding relative high efficiency and capture rates are reported in Table 8. Depending on the biomass and the electricity import/export prices, production cost can become lower as shown in section 4.5. Compared to fossil power plants (Tables $1 \& 2$ ) with carbon capture the biomass conversion into electricity and $\mathrm{H}_{2}$ reveals to be competitive.

\subsection{Economic evaluation}

The $\mathrm{H}_{2}$ production costs assessed previously depend strongly on the economic assumptions made in Table 5 . The sensitivity analysis varying the wood cost $\left[10-70 \$ / \mathrm{MWh}_{B M}\right]$ and the green electricity cost $\left[40-270 \$ / \mathrm{MWh}_{e}\right]$ shows the influence of the resource price on the competitiveness of the $\mathrm{H}_{2}$ production in Figure 12 for the configurations yielding a compromise between efficiency and $\mathrm{CO}_{2}$ capture (Table 8) and for the base case without capture (Table 7:B). With the initial assumption of $50 \$ / \mathrm{MWh}_{B M}$ for biomass from Switzerland [13] up to $60 \%$ of the production cost are attributed to wood purchase, whereas a decrease of the resource cost can reduce this fraction to around $20 \%$ and reduce the $\mathrm{H}_{2}$ production cost by nearly $50 \%$. According to [16], biomass prices as low as $7.2 \$_{2002} / \mathrm{MWh}$ can be expected for Latin and North America. Consequently, the competitiveness is highly influenced by the resource price and location. The assessed costs are still slightly higher than the one reported in [16] because of the higher investment cost, especially for the gasifier purchase. Contrary to their approach, the investment estimation method applied here rates the equipment with conventional design heuristics that take the operating conditions into account. As pilot plant data are used as reference for the design parameters of the gasifier, it can be expected to yield realistic figures. The conservative cost estimation might however 
overestimate the investment and consequently lead to higher production cost. Nevertheless, these biomass based $\mathrm{H}_{2}$ processes yielding efficiencies of $40-60 \%$ and production costs in the range of $65-262 \$ / \mathrm{MWh}_{H 2}$ can become a competitive option with regard to fossil resource depletion and climate change compared to conventional processes using fossil resources (Table 1). Considering a new hydrogen plant based on fossil resources [24] producing $\mathrm{H}_{2}$ with an efficiency of $60 \%$, production costs of $28 \$ / \mathrm{MWh}_{2}$ and $\mathrm{CO}_{2}$ emissions of $493 \mathrm{~kg} / \mathrm{MWh}_{\mathrm{H} 2}$ as a reference, $\mathrm{CO}_{2}$ avoidance cost ${ }^{1}$ in the range of $45-220 \$ / \mathrm{t}_{\mathrm{CO} 2}$ are assessed for the analyzed biomass based processes. In comparison, $\mathrm{CO}_{2}$ avoidance cost in the range of $2-56 \$ / t_{\mathrm{CO} 2}$ are assessed for fossil $\mathrm{H}_{2}$ production processes with $\mathrm{CO}_{2}$ capture in [24] .

For the electricity production processes without $\mathrm{CO}_{2}$ capture (Table 7:G/I) and with $\mathrm{CO}_{2}$ capture (Table 8 ) a sensitivity analysis on the wood cost $\left[10-70 \$ / \mathrm{MWh}_{B M}\right]$ (Figure 13) yields electricity production cost in the range of $89-362 \$ / \mathrm{MWh}_{e}$. Considering the low wood cost, the costs are in the range of the one reported in $[19](\approx 150-220 \$ / \mathrm{MWh})$. Compared to fossil power plants (Table 2) some scenarios with $\mathrm{CO}_{2}$ capture are promising regarding the future energy market, especially when high $\mathrm{CO}_{2}$ taxes are imposed. Considering a NGCC plant [24] with an efficiency of $57 \%$, production costs of $40 \$ / \mathrm{MWh}_{e}$ and $\mathrm{CO}_{2}$ emissions of $360 \mathrm{~kg} / \mathrm{MWh}_{e}$ as a reference, $\mathrm{CO}_{2}$ avoidance cost in the range of $98-254 \$ / t_{C O}$ are assessed for the analyzed biomass based processes. In comparison, $\mathrm{CO}_{2}$ avoidance cost in the range of $37-74 \$ / \mathrm{t}_{\mathrm{CO}}$ are assessed for an NGCC with $\mathrm{CO}_{2}$ capture in [24]. By the sensitivity analyses, it is shown that the variation of the resource price of a factor of 7 translates in a production cost increase of a factor of 4 due to the high weight of resource purchase in the total cost. Consequently, the resource price and location define the competitiveness of the biomass conversion processes. The analyses also highlight the importance of the process efficiency. The market price of electricity, fuel, biomass and $\mathrm{CO}_{2}$ taxes will define if it is more advantageous to produce $\mathrm{H}_{2}$ with or without electricity import as final product or to convert the $\mathrm{H}_{2}$ fuel directly into electricity with or without $\mathrm{CO}_{2}$ capture.

\subsection{Environmental impacts}

For the life cycle inventory, the method from the IPCC (IPCC07) is applied for the LCI flows identified in Figure 2. Following the approach of Gerber et al. [15], 1kJ of biomass entering the plant is considered as functional unit in order to make a consistent comparison of $\mathrm{H}_{2}$ and electricity production scenarios. The data available from the ecoinvent database [9] are used for the different contributions. For the electricity impact contribution, the Swiss mix for medium voltage electricity production at grid is considered. The amount of $\mathrm{CO}_{2}$ that is stored is accounted as a negative contribution of fossil $\mathrm{CO}_{2}$.

Regarding the climate change impact of $\mathrm{H}_{2}$ processes, Figure 14 shows the advantage of $\mathrm{CO}_{2}$ capture. $\mathrm{CO}_{2}$ capture for storage has a negative contribution (n) to the climate change impact which outweighs all the other positive contributions (p).

For the electricity generation processes, the benefit of $\mathrm{CO}_{2}$ capture on the climate change is highlighted in Figure 15. A large impact is attributed to the use of rape methyl ester (RME) produced from colza cultivated with insecticides and consumed for the cold gas cleaning, consequently alternative colza cultivation methods and the development of alternative cleaning technologies such as hot gas cleaning have to be analyzed.

With regard to $\mathrm{CO}_{2}$ emissions mitigation, processes based on renewable biomass have a huge potential, especially if $\mathrm{CO}_{2}$ capture and storage is implemented since this leads to a negative $\mathrm{CO}_{2}$ balance.

\footnotetext{
${ }^{1} \mathrm{CO}_{2}$ avoidance cost expressed in $\$ / \mathrm{t}_{\mathrm{CO} 2 \text {, avoided }}$ are defined by the ratio of the difference of the production cost and the $\mathrm{CO}_{2}$ emissions for a plant with capture and a reference plant without capture: $\frac{C O E_{C C}-C O E_{r e f}[\$ / M W h]}{C O 2_{\text {emit, ref }}-C O 2_{\text {emit }, C C}[\mathrm{kgCO} / \mathrm{MWh}]}$. For the biomass based plants, the $\mathrm{CO}_{2}$ emissions equal to the negative value of the $\mathrm{CO}_{2}$ captured since it is removed from the atmosphere.
} 


\section{Conclusion}

A systematic methodology based on thermo-economic and LCI models coupled with a multiobjective optimization algorithm has been applied to the conceptual design of integrated plants for $\mathrm{H}_{2}$ fuel, power and heat production. The competitiveness of $\mathrm{H}_{2}$ and electricity production and co-production process options are evaluated consistently with respect to energy efficiency, cost and environmental impacts. It is highlighted in particular, how appropriate energy integration and operating conditions optimization improve the process performance by maximizing the combined production of fuel, heat and power. Based on multi-objective optimizations with regard to energy efficiency and capital investment or $\mathrm{CO}_{2}$ capture rate, the trade-off between $\mathrm{H}_{2}$ and electricity generation and $\mathrm{CO}_{2}$ capture are assessed. Life cycle impact assessment underlined the climate change benefit of using renewable resources and capturing $\mathrm{CO}_{2}$. Overall energy efficiencies in the range of $60 \%$ are reached for $\mathrm{H}_{2}$ production and around $39 \%$ for electricity production with $\mathrm{CO}_{2}$ capture. Depending on the biomass price evolution, $\mathrm{H}_{2}$ production costs in the range of $65-262 \$ / \mathrm{MWh}_{H 2}$ and electricity production costs in the range of $89-362 \$ / \mathrm{MWh}_{e}$ are reported. With regard to conventional $\mathrm{H}_{2}$ and electricity production processes based on fossil resources, $\mathrm{CO}_{2}$ avoidance costs of $45-220 \$ / \mathrm{t}_{C O 2 \text {, avoided }}$ and $98-254 \$ / \mathrm{t}_{C O 2 \text {, avoided }}$ respectively, are computed. In comparison, the performances assessed in [24] for processes using fossil resources are for a NGCC plant $43-72 \$ / \mathrm{MWh}_{e}$ and $37-74 \$ / \mathrm{t}_{C O 2 \text {, avoided }}$, and for $\mathrm{H}_{2}$ plants $27-48 \$ / \mathrm{MWh}_{H 2}$

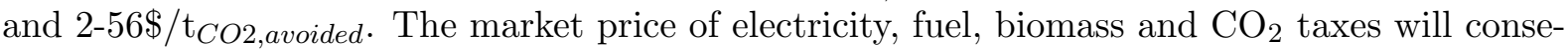
quently define the competitiveness of biomass conversion into $\mathrm{H}_{2}$ or electricity with or without $\mathrm{CO}_{2}$ capture. With regard to a future energy system promoting renewable resources and reduced greenhouse gas emissions, biomass based $\mathrm{H}_{2}$ and electricity production have to be considered as competitive alternatives.

\section{Acknowledgments}

This work was associated with the CARMA project funded by the Competence Center Environment and Sustainability (CCES) and the Competence Center Energy and Mobility (CCEM) of the Swiss federal institute domain.

\section{References}

[1] Abuadala, A., Dincer, I., Naterer, G., 2010. Exergy analysis of hydrogen production from biomass gasification. International Journal of Hydrogen Energy 35 (10), 4981-4990.

[2] Balat, H., Kirtay, E., 2010. Hydrogen from biomass - present scenario and future prospects. International Journal of Hydrogen Energy 35 (14), 7416-7426.

[3] Bartels, J., Pate, M., Olson, N., 2010. An economic survey of hydrogen production from conventional and alternative energy sources. International Journal of Hydrogen Energy 35 (16), 8371-8384.

[4] Bernier, E., Maréchal, F., Samson, R., 2010. Multi-objective design optimization of a natural gas-combined cycle with carbon dioxide capture in a life cycle perspective. Energy $35(2), 1121-1128$.

[5] Bhattacharya, A., Manna, D., Paul, B., Datta, A., 2011. Biomass integrated gasification combined cycle power generation with supplementary biomass firing: Energy and exergy based performance analysis. Energy 36 (5), 2599 - 2610. 
[6] Carpentieri, M., Corti, A., Lombardi, L., 2005. Life cycle assessment LCA of an integrated biomass gasification combined cycle IBGCC with CO2 removal. Energy Conversion and Management 46, 1790-1808.

[7] Cohce, M., Dincer, I., Rosen, M., 2010. Thermodynamic analysis of hydrogen production from biomass gasification. International Journal of Hydrogen Energy 35, 4970-4980.

[8] Corti, A., Lombardi, L., 2004. Biomass integrated gasification combined cycle with reduced CO2 emissions: Performance analysis and life cycle assessment (LCA). Energy 29 (12-15), $2109-2124$.

[9] Ecoinvent, last visited 08/2011. http://www.ecoinvent.ch/.

[10] Evers, A., 2010. The Hydrogen Society... More Than Just a Vision? . H2YDROGEIT Verlag.

[11] Gassner, M., Maréchal, F., 2008. Thermo-economic optimisation of the integration of electrolysis in synthetic natural gas production from wood. Energy 33 (2), 189 - 198.

[12] Gassner, M., Maréchal, F., 2009. Methodology for the optimal thermo-economic, multiobjective design of thermochemical fuel production from biomass. Computers \& Chemical Engineering 33 (3), 769-781.

[13] Gassner, M., Maréchal, F., 2009. Thermo-economic process model for the thermochemical production of Synthetic Natural Gas (SNG) from lignocellulosic biomass. Biomass \& Bioenergy 33 (11), 1587-1604.

[14] Gassner, M., Maréchal, F., 2009. Thermodynamic comparison of the FICFB and Viking gasification concepts. Energy 34 (10), $1744-1753$.

[15] Gerber, L., Gassner, M., Maréchal, F., 2011. Systematic integration of LCA in process systems design: Application to combined fuel and electricity production from lignocellulosic biomass. Computers \& Chemical Engineering 35 (7), 1265 - 1280.

[16] Hamelinck, C., Faaij, A., 2002. Future prospects for production of methanol and hydrogen from biomass. Journal of Power Sources 111 (1), 1-22.

[17] Jee, J., Kim, M., Lee, C., 2001. Adsorption characteristics of hydrogen mixtures in a layered bed: Binary, ternary, and Five-Component mixtures. Industrial \& Engineering Chemistry Research 40 (3), 868-878.

[18] Klett, M., White, J., Schoff, R., Buchanan, T., 2002. Hydrogen production facilities plant performance and cost comparisons. Tech. rep., Report prepared for the USDOE National Energy Technology Laboratory (NETL) by Parsons Infrastructure and Technology Group, Inc.

[19] Klimantos, P., Koukouzas, N., Katsiadakis, A., Kakaras, E., 2009. Air-blown biomass gasification combined cycles (BGCC): System analysis and economic assessment. Energy 34 (5), $708-714$.

[20] Kvamsdal, H., Jordal, K., Bolland, O., 2007. A quantitative comparison of gas turbine cycles with capture. Energy 32 (1), $10-24$.

[21] Mann, M., Spath, P., 1997. Life cycle assessment of a biomass gasification combined-cycle system. Technical report, National Renewable Energy Laboratory. 
[22] Maréchal, F., Kalitventzeff, B., 1997. Identification of the optimal pressure levels in steam networks using integrated combined heat and power method. Chemical Engineering Science 52 (17), 2977-2989.

[23] Maréchal, F., Kalitventzeff, B., 1998. Process integration: Selection of the optimal utility system. Computers \& Chemical Engineering 22, 149-156.

[24] Metz, B., Davidson, O., de Coninck, H., Loos, M., Meyer, L., 2005. IPCC special report on carbon dioxide capture and storage. Tech. rep., Cambridge University Press.

[25] Molyneaux, A., Leyland, G., Favrat, D., 2010. Environomic multi-objective optimisation of a district heating network considering centralized and decentralized heat pumps. Energy 35 (2), 751-758.

[26] Morandin, M., Toffolo, A., Lazzaretto, A., Maréchal, F., Ensinas, A., Nebra, S., 2011. Synthesis and parameter optimization of a combined sugar and ethanol production process integrated with a CHP system. Energy 36 (6), 3675 - 3690.

[27] Radgen, P., Cremer, C., Warkentin, S., Gerling, P., May, F., Knopf, S., 2005. Verfahren zur CO2-Abscheidung und -Speicherung. Abschlussbericht Forschungsbericht 20341110 UBA-FB 000938, Frauenhofer-Institut für Systemtechnik und Innovationsforschung, Bundesantstalt für Geowissenschaften und Rohstoffe.

[28] Simbeck, D., Chang, E., 2002. Hydrogen supply: Cost estimate for hydrogen PathwaysScoping analysis. Tech. Rep. NREL/SR-540-32525, National Renewable Energy Laboratory.

[29] Spath, P., Aden, A., Eggeman, T., Ringer, M., Wallace, B., Jechura, J., 2005. Biomass to hydrogen production detailed design and economics utilizing the battelle columbus laboratory indirectly heated gasifier. Technical Report NREL/TP-510-37408, National Renewable Energy Laboratory.

[30] Spath, P., Mann, M., Amos, W., 2003. Update of hydrogen from biomass-determination of the delivered cost of hydrogen. Milestone Completion Report NREL/MP-510-33112, National Renewable Energy Laboratory.

[31] Tock, L., Gassner, M., Maréchal, F., 2010. Thermochemical production of liquid fuels from biomass: Thermo-economic modeling, process design and process integration analysis. Biomass and Bioenergy 34, 1838-1854.

[32] Tock, L., Marechal, F., 2012. Process design optimization strategy to develop energy and cost correlations of CO2 capture processes. Submitted to the 22nd European Symposium on Computer Aided Process Engineering, 17-20 June 2012, London.

[33] Toonssen, R., Woudstra, N., Verkooijen, A., 2008. Exergy analysis of hydrogen production plants based on biomass gasification. International Journal of Hydrogen Energy 33 (15), 4074-4082.

[34] Turton, R., 2009. Analysis, Synthesis, and Design of Chemical Processes, 3rd Edition. Prentice Hall, Upper Saddle River, N.J.

[35] Ulrich, G., Vasudevan, P., 2003. A Guide to Chemical Engineering Process Design and Economics a Practical Guide, 2nd Edition. CRC, Boca Raton, Fla.

[36] Williams, R., Parker, N., Yang, C., Ogden, J., Jenkins, B., 2007. H2 production via biomass gasification. Advanced Energy Pathways AEP Project, Task 4.1 Technology Assessments of Vehicle fuels and technologies, Public interest energy research PIER Program, California Energy Commission, UC Davis, Institute of Transportation Studies (ITS-Davis). 


\section{List of Tables}

1 Reference $\mathrm{H}_{2}$ production plants performance. . . . . . . . . . . . . . . . 14

2 Reference power plants performance without and with $\mathrm{CO}_{2}$ capture. . . . . . . . 14

3 Parameters for the $\mathrm{H}_{2}$ purification. . . . . . . . . . . . . . . . . 14

4 Operating conditions of the process units and feasible range for optimization. . . 14

5 Assumptions for the economic analysis. . . . . . . . . . . . . . 15

6 Feasible range for optimization of the steam network design and the gas turbine. 15

$7 \quad$ Investigated process configurations characteristics. . . . . . . . . . . . . 15

8 Process performance of selected optimal configurations. . . . . . . . . . . . 16 
Table 1: Reference $\mathrm{H}_{2}$ production plants performance.

\begin{tabular}{lcccc}
\hline Process & $\mathrm{CO}_{2}$ capture [\%] & $\epsilon[\%]$ & {$\left[\$ / \mathrm{MWh}_{H 2}\right]$} & Ref. \\
\hline Natural gas & 0 & $83.9(\mathrm{HHV})$ & 18.9 & {$[18]$} \\
Natural gas & 71 & $78.6(\mathrm{HHV})$ & 20.2 & {$[18]$} \\
Coal (Texaco gasif.) & 0 & $63.7(\mathrm{HHV})$ & 31.6 & {$[3]$} \\
Coal (Texaco gasif.) & 87 & $59(\mathrm{HHV})$ & 37.8 & {$[3]$} \\
Biomass (FICFB, CGC) & - & 57.7 & - & {$[33]$} \\
Biomass & - & $51-60$ & $29-40$ & {$[16]$} \\
\hline
\end{tabular}

Table 2: Reference power plants performance without and with $\mathrm{CO}_{2}$ capture.

\begin{tabular}{lcccccc}
\hline Type & $\mathrm{CO}_{2}$ capture [\%] & $\epsilon[\%]$ & $\mathrm{gCO}_{2} / \mathrm{kWh}_{e}$ & $\mathrm{COE}\left[\$ / \mathrm{MWh}_{e}\right]$ & $\$ / \mathrm{t} \mathrm{CO}_{2, \text { avoided }}$ & Ref. \\
\hline $\mathrm{PC}$ & 0 & $41-45$ & $736-811$ & $43-52$ & - & {$[24]$} \\
PC -CC & $85-90$ & $30-35$ & $92-145$ & $62-86$ & $29-51$ & {$[24]$} \\
IGCC & 0 & $38-47$ & $682-846$ & $41-61$ & - & {$[24]$} \\
IGCC -CC & $85-90$ & $31-40$ & $65-152$ & $54-79$ & $13-37$ & {$[24]$} \\
NGCC & 0 & $55-58$ & $344-379$ & $31-50$ & - & {$[24]$} \\
NGCC -CC & $85-90$ & $47-50$ & $40-66$ & $43-72$ & $37-74$ & {$[24]$} \\
IBGCC & 0 & 37 (HHV) & - & 67.5 & - & {$[21]$} \\
IBGCC -CC & 80 & 33.94 & 178 & - & - & {$[6]$} \\
\hline
\end{tabular}

Table 3: Parameters for the $\mathrm{H}_{2}$ purification.

\begin{tabular}{llc}
\hline Section & Specification & Value \\
\hline Chem. abs. & Thermal $\dot{Q} @ 150^{\circ} \mathrm{C}$ & $3.7 \mathrm{MJ} / \mathrm{kg} \mathrm{CO} 2$ \\
& Electric Power & $1.0 \mathrm{MJ} / \mathrm{kg} \mathrm{CO} 2$ \\
\hline PSA & Adsorption P & $10 \mathrm{bar}$ \\
& Purging P & $0.1 \mathrm{bar}$ \\
& $\mathrm{H}_{2}$ recovery & $90 \%$ \\
\hline
\end{tabular}

Table 4: Operating conditions of the process units and feasible range for optimization.

\begin{tabular}{|c|c|c|}
\hline Operating parameter & Nominal & Range \\
\hline \multicolumn{3}{|c|}{ Drying } \\
\hline Temperature (in) $[\mathrm{K}]$ & 473 & - \\
\hline$\theta_{\text {wood,out }}[\mathrm{wt} \%]$ & 20 & {$[5-35]$} \\
\hline \multicolumn{3}{|c|}{ Gasification } \\
\hline Pressure [bar] & 1 & [1-15] \\
\hline Temperature $[\mathrm{K}]$ & 1123 & [1000-1200] \\
\hline Steam/biomass $[\% \mathrm{wt}]$ & 50 & - \\
\hline \multicolumn{3}{|c|}{ SMR } \\
\hline Temperature $[\mathrm{K}]$ & 1138 & [950-1200] \\
\hline \multicolumn{3}{|c|}{ WGS } \\
\hline Pressure [bar] & 25 & [1-25] \\
\hline Temperature HTS $[\mathrm{K}]$ & 623 & {$[573-683]$} \\
\hline Temperature LTS $[\mathrm{K}]$ & 453 & {$[473-573]$} \\
\hline $\mathrm{H}_{2} \mathrm{O} / \mathrm{CO}$ molar ratio [-] & 2 & {$[0.2-4]$} \\
\hline
\end{tabular}


Table 5: Assumptions for the economic analysis.

\begin{tabular}{lr}
\hline Parameter & Value \\
\hline Marshall and Swift Index & 1473.3 \\
Dollar exchange rate (€_US $\$)$ & $1.5 \mathrm{US} \$ / €$ \\
Expected lifetime & 15 years \\
Interest rate & $6 \%$ \\
Yearly operation & $8000 \mathrm{~h} /$ year \\
Operators $[13]$ & $4 \mathrm{p} . / \mathrm{shift}$ \\
Operator's salary & $91^{\prime} 070 \$ /$ year \\
Wood costs $\left(\theta_{\text {wood }}=50 \% \mathrm{wt}\right)$ & $50 \$ / \mathrm{MWh}$ \\
Electricity price (green) & $270 \$ / \mathrm{MWh}$ \\
\hline
\end{tabular}

Table 6: Feasible range for optimization of the steam network design and the gas turbine.

\begin{tabular}{llc}
\hline Operating parameter & Unit & Range \\
\hline 1st Production level & bar & {$[90-130]$} \\
2nd Production level & bar & {$[70-110]$} \\
Superheating temperature & $\mathrm{K}$ & {$[623-823]$} \\
1st Utilization level & $\mathrm{K}$ & {$[300-523]$} \\
2nd Utilization level & $\mathrm{K}$ & 510 \\
Condensation level & $\mathrm{K}$ & 292 \\
\hline Combustion T & $\mathrm{K}$ & {$[700-900]$} \\
Turbine T & $\mathrm{K}$ & 1500 \\
\hline
\end{tabular}

Table 7: Investigated process configurations characteristics.

\begin{tabular}{|c|c|c|c|c|c|c|c|c|c|c|c|c|c|c|}
\hline Configuration a & $\mathrm{A}$ & B & $\mathrm{C}$ & $\mathrm{C}_{\text {opt }}$ & $\mathrm{D}$ & $\mathrm{D}_{\text {opt }}$ & E & $\mathrm{F}$ & G & $\mathrm{H}$ & $\mathrm{H}_{\text {opt }}$ & $\mathrm{I}$ & $\mathrm{J}$ & $J_{\text {opt }}$ \\
\hline \multirow{2}{*}{\multicolumn{9}{|c|}{$\mathrm{H}_{2}$ Process }} & \multirow{2}{*}{\multicolumn{6}{|c|}{$\begin{array}{c}\text { Electricity generation } \\
\text { Process Parameters }\end{array}$}} \\
\hline \multicolumn{3}{|c|}{$\begin{array}{l}\text { Process Parameters } \\
\end{array}$} & & & & & & & & & & & & \\
\hline Products & $\mathrm{H}_{2}$ & $\mathrm{H}_{2}$ & $\mathrm{H}_{2}$ & $\mathrm{H}_{2}$ & $\mathrm{H}_{2}$ & $\mathrm{H}_{2}$ & $\mathrm{H}_{2}$ & $\mathrm{H}_{2}$ & $\dot{E}$ & $\dot{E}$ & $\dot{E}$ & $\dot{E}$ & $\dot{E}$ & $\dot{E}$ \\
\hline Carbon capture [\%] & $\mathrm{y}$ & $\mathrm{n}$ & $\mathrm{y}$ & $\mathrm{y}$ & $\mathrm{y}$ & $\mathrm{y}$ & $\mathrm{y}$ & $\mathrm{y}$ & $\mathrm{n}$ & $\mathrm{y}$ & $\mathrm{y}$ & $\mathrm{n}$ & $\mathrm{y}$ & $\mathrm{y}$ \\
\hline PSA & $\mathrm{y}$ & $\mathrm{y}$ & $\mathrm{y}$ & $\mathrm{y}$ & $\mathrm{y}$ & $\mathrm{y}$ & $\mathrm{n}$ & $\mathrm{n}$ & $\mathrm{y}$ & $\mathrm{y}$ & $\mathrm{y}$ & $\mathrm{n}$ & $\mathrm{n}$ & $\mathrm{n}$ \\
\hline PG burning & $\mathrm{y}$ & $\mathrm{y}$ & $\mathrm{y}$ & $\mathrm{y}$ & $\mathrm{y}$ & $\mathrm{n}$ & $\mathrm{y}$ & $\mathrm{y}$ & $\mathrm{n}$ & $\mathrm{n}$ & $\mathrm{n}$ & $\mathrm{n}$ & $\mathrm{n}$ & $\mathrm{n}$ \\
\hline GT $\mathrm{H}_{2}$ impure & $\mathrm{n}$ & $\mathrm{n}$ & $\mathrm{n}$ & $\mathrm{n}$ & $\mathrm{n}$ & $\mathrm{y}$ & $\mathrm{n}$ & $\mathrm{n}$ & $\mathrm{n}$ & $\mathrm{n}$ & $\mathrm{n}$ & $\mathrm{y}$ & $\mathrm{y}$ & $\mathrm{y}$ \\
\hline GT $\mathrm{H}_{2}$ pure & $\mathrm{n}$ & $\mathrm{n}$ & $\mathrm{n}$ & $\mathrm{n}$ & $\mathrm{n}$ & $\mathrm{n}$ & $\mathrm{n}$ & $\mathrm{n}$ & $\mathrm{y}$ & $\mathrm{y}$ & $\mathrm{y}$ & $\mathrm{n}$ & $\mathrm{n}$ & $\mathrm{n}$ \\
\hline HP & $\mathrm{n}$ & $\mathrm{n}$ & $387 / 478 \mathrm{~K}$ & $387 / 478 K$ & $387 / 478 \mathrm{~K}$ & $387 / 478 \mathrm{~K}$ & $\mathrm{n}$ & $387 / 478 \mathrm{~K}$ & $\mathrm{n}$ & $387 / 478 \mathrm{~K}$ & $387 / 478 \mathrm{~K}$ & $\mathrm{n}$ & $387 / 478 \mathrm{~K}$ & $\mathrm{n}$ \\
\hline Steam network: & $\mathrm{n}$ & $\mathrm{n}$ & $\mathrm{y}$ & $\mathrm{y}$ & $\mathrm{y}$ & $\mathrm{y}$ & $\mathrm{y}$ & $\mathrm{y}$ & & $\mathrm{y}$ & & & $\mathrm{y}$ & \\
\hline Production levels [bar] & - & - & 140 & $135 \& 95$ & 125 & 128 & 93 & $125 \& 93$ & $125 \& 93$ & $125 \& 93$ & $105 \& 60$ & $125 \& 93$ & $125 \& 93$ & $128 \& 60$ \\
\hline Consumption levels $[\mathrm{K}]$ & - & - & $513 \& 473$ & $505 \& 434$ & $473 \& 300$ & $483 \& 430$ & 300 & $513 \& 300$ & $513 \& 300$ & $513 \& 300$ & $428 \& 300$ & $513 \& 300$ & $510 \& 300$ & $431 \& 300$ \\
\hline \multicolumn{9}{|c|}{ Power Balance } & \multicolumn{6}{|c|}{ Power Balance } \\
\hline Consumption $[\mathrm{kW} / \mathrm{MW}]$ & 136.7 & 72.5 & 169.7 & 153.3 & 120.6 & 119.6 & 127.5 & 100.8 & 91.8 & 221.5 & 102.8 & 89.5 & 176.6 & 77.4 \\
\hline $\mathrm{HP}[\mathrm{kW} / \mathrm{MW}]$ & 0 & 0 & 40.4 & 35.9 & 27.6 & 8.1 & 35.9 & 28.1 & 0 & 53.1 & 0.3 & 0 & 53.3 & 0 \\
\hline Steam network $[\mathrm{kW} / \mathrm{MW}]$ & 0 & 0 & 25.7 & 10.1 & 37.7 & 29.3 & 31.2 & 28.1 & 115.6 & 132.6 & 108.2 & 100.4 & 113.9 & 105.7 \\
\hline Gas turbine $[\mathrm{kW} / \mathrm{MW}]$ & 9.1 & 28.9 & 9.9 & 30.4 & 110.5 & 98.4 & 6.0 & 100.8 & 425.5 & 414.7 & 389.3 & 338.8 & 307.9 & 296.2 \\
\hline Net electricity $[\mathrm{kW} / \mathrm{MW}]$ & -127.6 & -43.6 & -174.5 & -148.7 & 0 & 0 & -126.2 & 0 & 449.3 & 272.7 & 394.4 & 349.7 & 191.9 & 324.5 \\
\hline \multicolumn{9}{|c|}{ Performance } & \multicolumn{6}{|c|}{ Performance } \\
\hline $\mathrm{H}_{2}$ yield $\left[\mathrm{g} / \mathrm{kg}_{\text {Biomass }}\right]$ & 79.8 & 92.4 & 102.9 & 107.1 & 68.7 & 83.8 & 96.7 & 72.2 & 0 & 0 & 0 & 0 & 0 & 0 \\
\hline $\mathrm{H}_{2}$ purity [mol\%] & 99.8 & 80.7 & 99.8 & 99.3 & 99.8 & 98.7 & 97.4 & 97.4 & 80.7 & 99.8 & 98.7 & 69.1 & 97.4 & 63.2 \\
\hline $\mathrm{H}_{2}$ production $[\mathrm{t} / \mathrm{d}]$ & 140.7 & 162.8 & 181.4 & 188.7 & 121.1 & 147.7 & 170.5 & 127.3 & 0 & 0 & 0 & 0 & 0 & 0 \\
\hline Energy $\mathrm{H}_{2}[\mathrm{~kW} / \mathrm{MW}]$ & 514.3 & 596.9 & 663 & 696.5 & 442.2 & 550.1 & 626.9 & 468.1 & 0 & 0 & 0 & 0 & 0 & 0 \\
\hline $\mathrm{CO}_{2}$ capture [\%] & 44.9 & 0 & 57.9 & 52.3 & 38.6 & 25 & 53.3 & 39.8 & 0 & 78.2 & 22.4 & 0 & 78.2 & 24.9 \\
\hline $\mathrm{gCO}_{2}$ captured/kWh & 316 & 0 & 316 & 271 & 316 & 164 & 308 & 307 & 0 & 1037 & 205 & 0 & 1474 & 278 \\
\hline$\epsilon_{t o t}[\%]$ & 45.6 & 57.2 & 56.4 & 60.6 & 44.2 & 55 & 55.6 & 46.8 & 44.9 & 27.3 & 39.4 & 34.9 & 19.2 & 32.4 \\
\hline$\epsilon_{e q}[\%]$ & 29.1 & 52.1 & 35.8 & 43.7 & 44.2 & 55 & 40.1 & 46.8 & - & - & - & - & - & - \\
\hline$\epsilon_{H 2}[\%]$ & 51.4 & 59.7 & 66.3 & 69.6 & 44.2 & 55 & 62.7 & 46.8 & 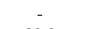 & - & - & - & - & - \\
\hline$\epsilon_{e x}[\%]$ & 39.9 & 49.7 & 49.6 & 53.1 & 38.2 & 47.5 & 48.7 & 40.4 & 39.9 & 24.3 & 35.1 & 31.1 & 17.1 & 28.9 \\
\hline \multicolumn{9}{|c|}{ Economics } & \multicolumn{6}{|c|}{ Economics } \\
\hline Investment [M\$] & 424 & 421 & 525 & 401 & 555 & 361 & 461 & 511 & 521 & 600 & 416 & 446 & 529 & 333 \\
\hline Annualized Inv. [\$/MWh] & 27.9 & 23.9 & 26.8 & 19.5 & 42.5 & 22.2 & 24.9 & 36.9 & 39.2 & 74.5 & 35.7 & 43.2 & 93.4 & 34.7 \\
\hline [\$/MWh] & 21.7 & 18.7 & 19.4 & 15.5 & 30.2 & 18.5 & 18.8 & 26.9 & 28.5 & 51.6 & 28.0 & 33.1 & 67.4 & 29.8 \\
\hline Wood cost [\$/MWh] & 95.7 & 82.4 & 74.2 & 70.6 & 111.3 & 89.4 & 78.5 & 105.1 & 109.5 & 180.4 & 124.8 & 140.7 & 256.3 & 151.6 \\
\hline Electricity cost $[\$ / \mathrm{MWh}]$ & 65.9 & 19.4 & 69.9 & 42.5 & 0 & 0 & 53.5 & 0 & 0 & 0 & 0 & 0 & 0 & 0 \\
\hline Production cost [\$/MWh] & 211.2 & 144.4 & 190.3 & 148.1 & 184 & 130.1 & 175.7 & 169 & 177.2 & 306.5 & 188.5 & 217 & 417 & 216.1 \\
\hline \multicolumn{9}{|c|}{ Environmental Impact (GWP 100) } & \multicolumn{6}{|c|}{ nental Impact (GWP 100) } \\
\hline
\end{tabular}

${ }^{\mathrm{a}}$ For the different technology options: $\mathrm{n}=$ not included, $\mathrm{y}=$ yes included. The net electricity output expressed in kW of electricity per MW of biomass is negativ it generates electricity. For $\mathrm{H}_{2}$ processes the costs are expressed in $\$ / \mathrm{MWh}_{\mathrm{H}}$ while for electricity generation they are expressed in $\$ / \mathrm{MWh}$. 
Table 8: Process performance of selected optimal configurations.

\begin{tabular}{lcc||cc}
\hline Process & $\mathrm{H}_{2} \dot{E}$ import & $\mathrm{H}_{2}$ self-sufficient & $\dot{E}$ GT H2 pure & $\dot{E}$ GT H2 impure \\
\hline$\epsilon_{\text {tot }}[\%]$ & 60.6 & 40.2 & 32.5 & 27.5 \\
$\mathrm{CO}_{2}$ capture [\%] & 65.1 & 74.4 & 75.2 & 56.4 \\
$\mathrm{gCO}_{2}$ captured $/ \mathrm{kWh}$ & 324 & 668 & 835 & 741 \\
$10^{-5} \mathrm{~kg} \mathrm{CO} 2_{e q} / \mathrm{kJ}$ & -6.4 & -6.6 & -4.8 \\
Investment $[\mathrm{M} \$$ ] & -5.5 & 651 & 777 & 532 \\
Production cost $[\$ / \mathrm{MWh}]$ & 129.7 & 214.1 & 284.3 & 291.3 \\
\hline
\end{tabular}




\section{List of Figures}

1 Design methodology: Thermo-environomic optimization [15] . . . . . . . . . 18

2 Flowsheet of the investigated biomass conversion processes with recycling options including thermo-economic and LCI model flows. The cross points A and B illustrate the different options with regard to $\mathrm{H}_{2}$ and/or electricity generation. . 18

3 Integrated composite curves for $\mathrm{H}_{2}$ process with and without $\mathrm{CO}_{2}$ capture (Table

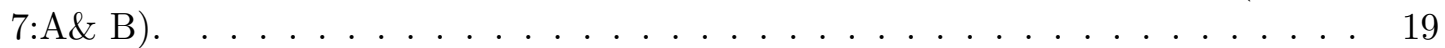

4 Integrated composite curve for a base case $\mathrm{H}_{2}$ process with net $\dot{E}$ import and with steam network integration (config. C). . . . . . . . . . . . . . 19

5 Integrated composite curve for a self-sufficient $\mathrm{H}_{2}$ process with steam network integration (config. D) . . . . . . . . . . . . . . . . . . 20

6 Integrated composite curve for the $\dot{E}$ production without $\mathrm{CO}_{2}$ capture and with steam network integration (config. G) . . . . . . . . . . . . . . . . 20

7 Integrated composite curve for the $\dot{E}$ production with $\mathrm{CO}_{2}$ capture and with steam network integration (config. H) . . . . . . . . . . . . . . . 21

8 Optimal solutions in the Pareto domain for $\mathrm{H}_{2}$ processes (config. C\& D) and $\dot{E}$ generation processes (config. I\& $\mathrm{H}$ ) with regard to efficiency and investment. . . 21

9 Optimal solutions in the Pareto domain for $\mathrm{H}_{2}$ processes (config. $\mathrm{C} \& \mathrm{D}$ ) and $\dot{E}$ generation processes (config. I\& $\mathrm{H}$ ) with regard to efficiency and $\mathrm{CO}_{2}$ capture rate. 22

10 Integrated composite curve for an optimized $\mathrm{H}_{2}$ process with net $\dot{E}$ import and steam network integration $\left(\right.$ config. $\mathrm{C}_{\text {opt }}$ ) . . . . . . . . . . . . . . 22

11 Integrated composite curve for an optimized self-sufficient $\mathrm{H}_{2}$ process with steam network integration (config. $\mathrm{D}_{\text {opt }}$ ) . . . . . . . . . . . . . . . 23

12 Sensitivity analysis of the wood cost on the hydrogen production cost $\left[\$ / \mathrm{MWh}_{\mathrm{H} 2}\right]$ for different $\mathrm{H}_{2}$ scenarios (Table $7: \mathrm{B} \&$ Table 8). . . . . . . . . . . . . . . 23

13 Sensitivity analysis of the wood cost on the electricity generation cost $\left[\$ / \mathrm{MWh}_{e}\right]$ for different scenarios (Table $7: G / I \&$ Table 8 ). . . . . . . . . . . . . . . . 24

14 Comparison of the climate change impact of the $\mathrm{H}_{2}$ generation processes (Table $7: \mathrm{B} / \mathrm{C} / \mathrm{D}$ ) based on impact method IPCC07 for 1kJ of biomass. . . . . . . . . 25

15 Comparison of the climate change impact of the electricity generation processes (Table 7:G-H) based on impact method IPCC07 for 1kJ of biomass. . . . . . . . 26 


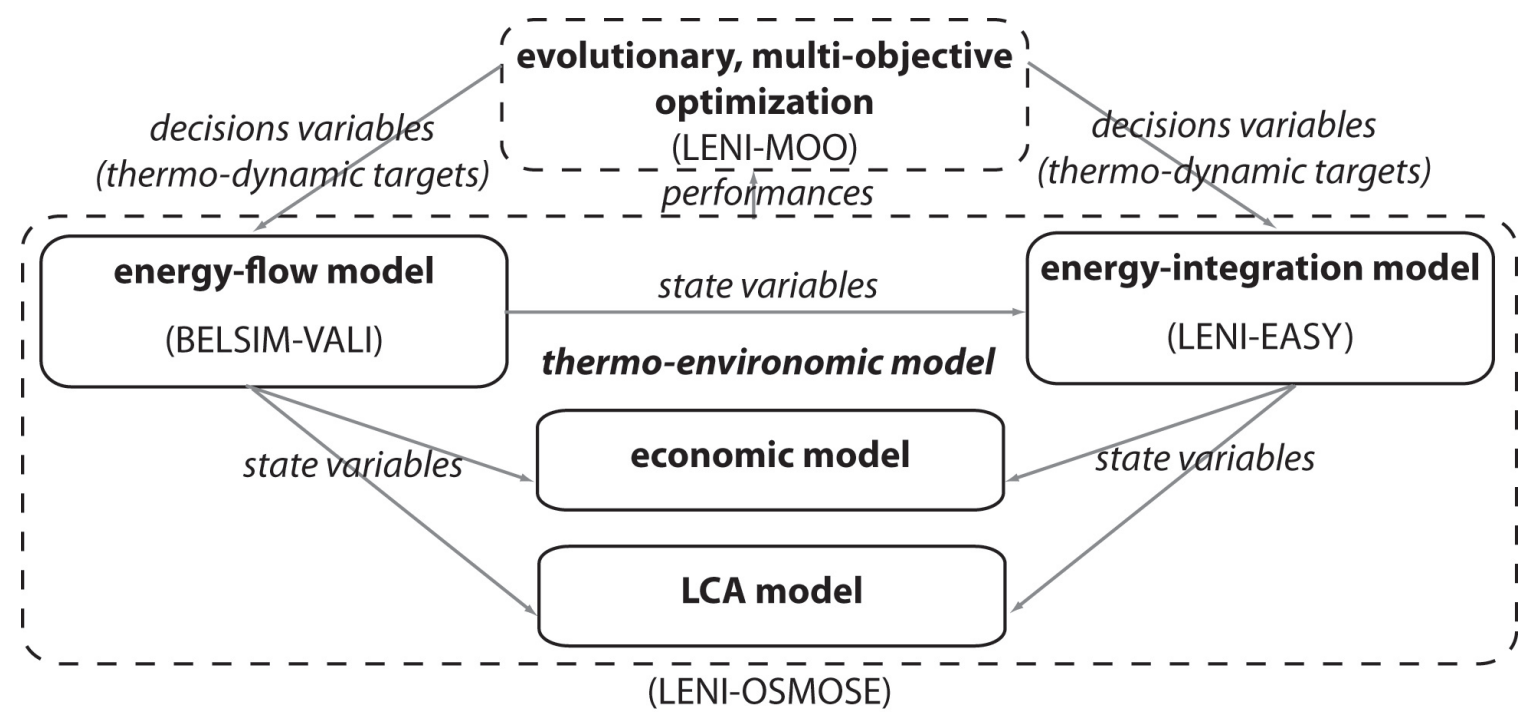

Figure 1: Design methodology: Thermo-environomic optimization [15]

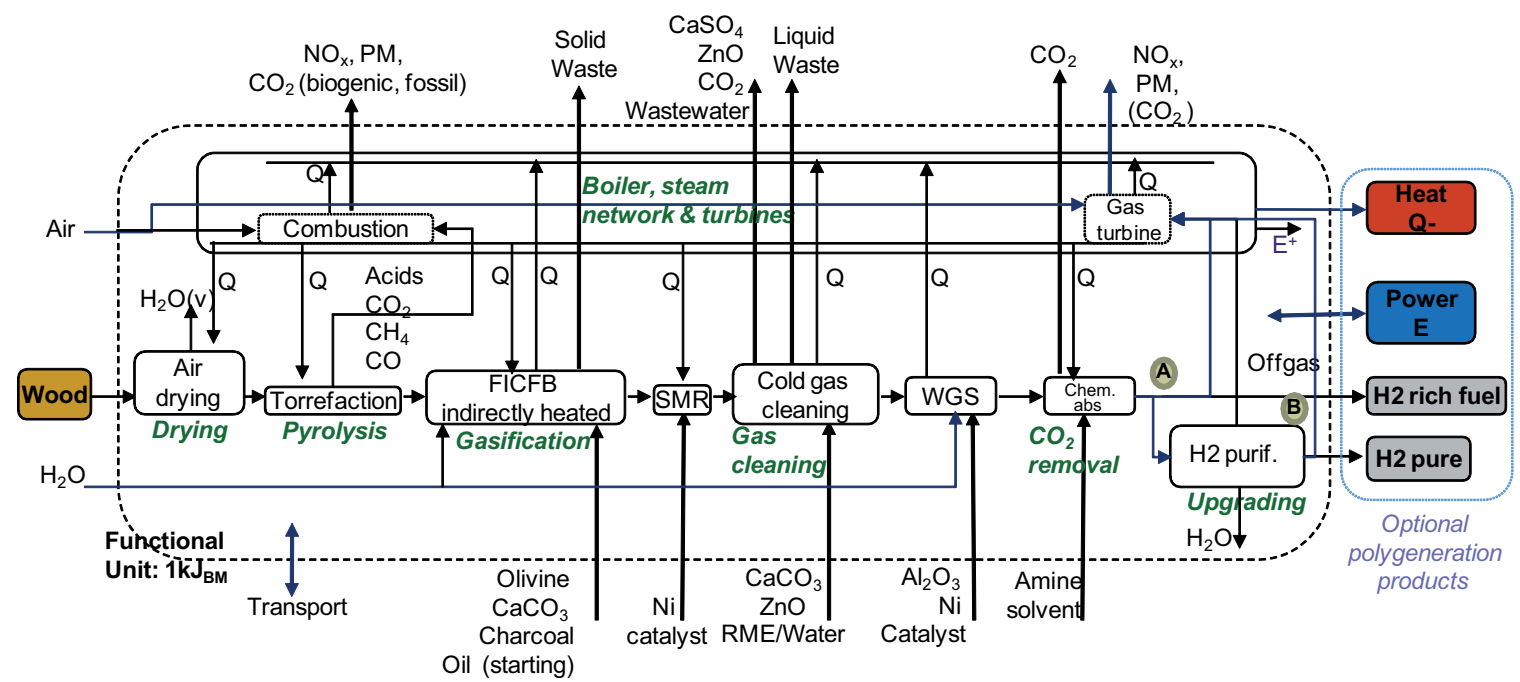

Figure 2: Flowsheet of the investigated biomass conversion processes with recycling options including thermo-economic and LCI model flows. The cross points A and B illustrate the different options with regard to $\mathrm{H}_{2}$ and/or electricity generation. 


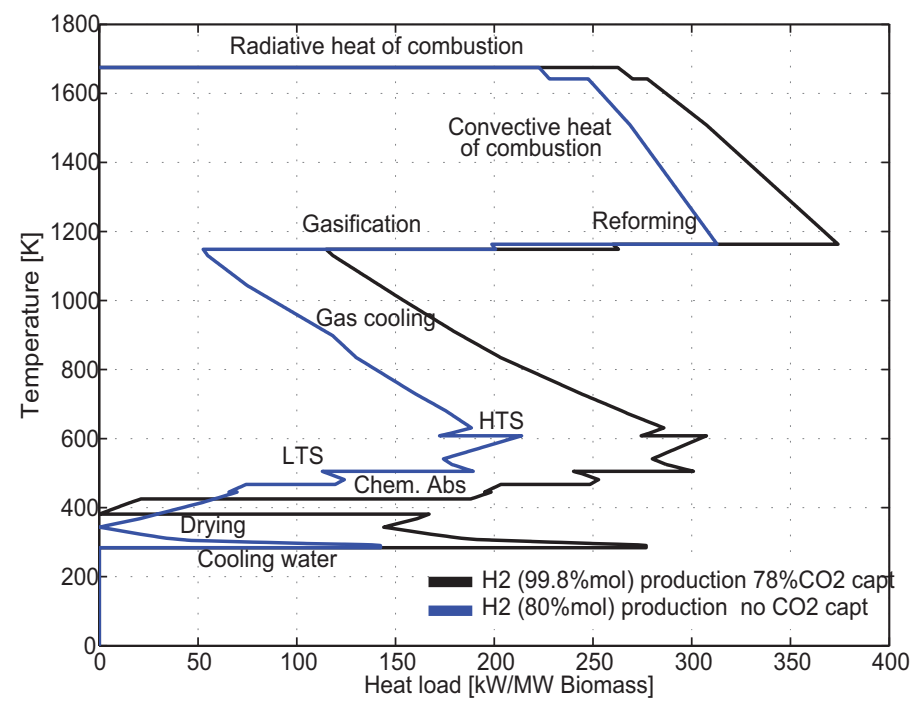

Figure 3: Integrated composite curves for $\mathrm{H}_{2}$ process with and without $\mathrm{CO}_{2}$ capture (Table $7: \mathrm{A} \& \mathrm{~B})$.

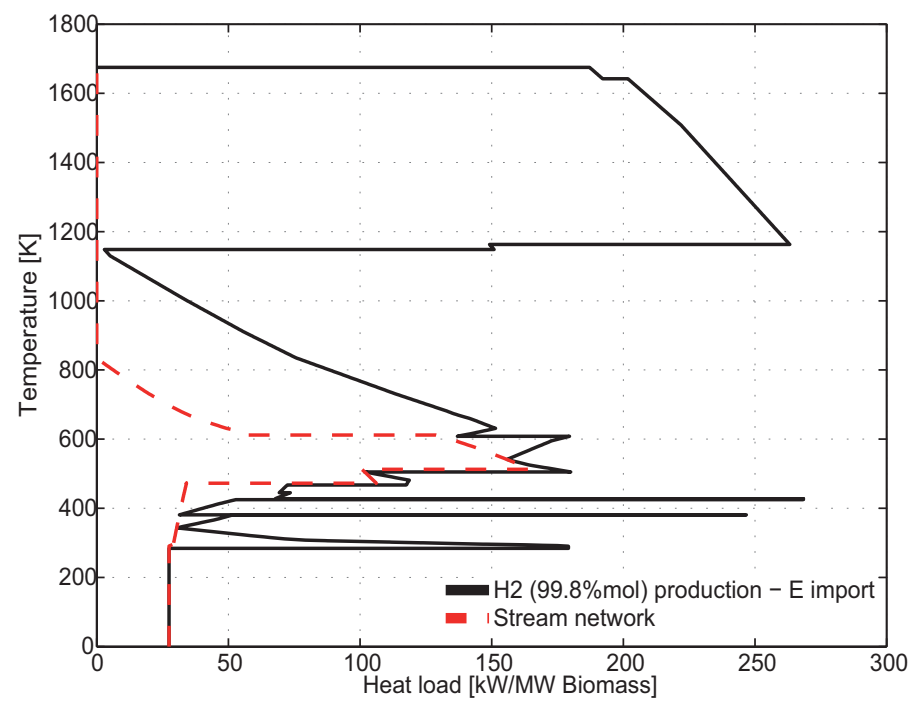

Figure 4: Integrated composite curve for a base case $\mathrm{H}_{2}$ process with net $\dot{E}$ import and with steam network integration (config. C). 


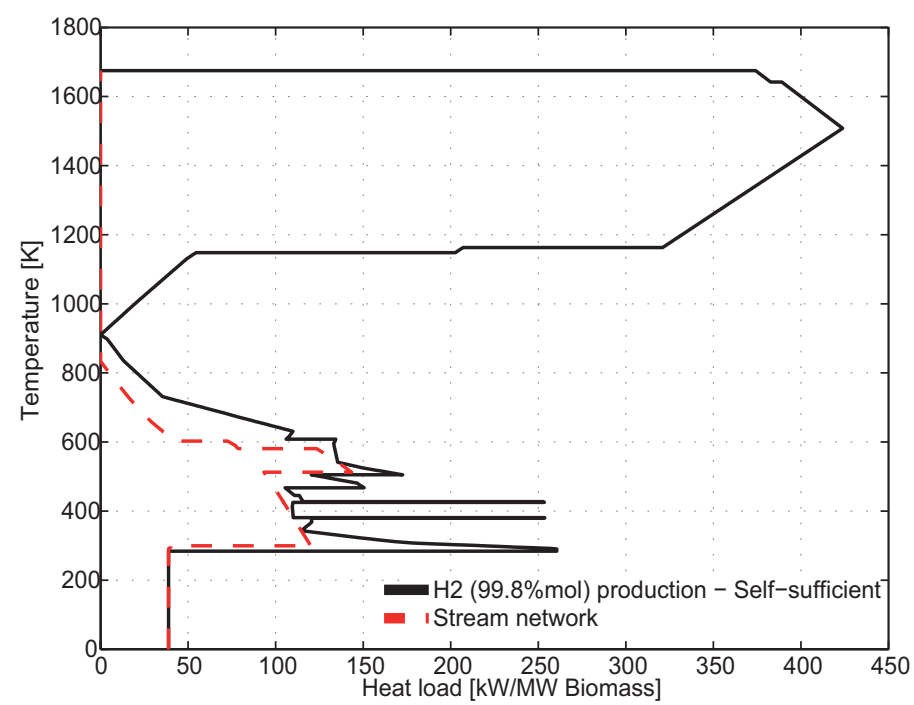

Figure 5: Integrated composite curve for a self-sufficient $\mathrm{H}_{2}$ process with steam network integration (config. D).

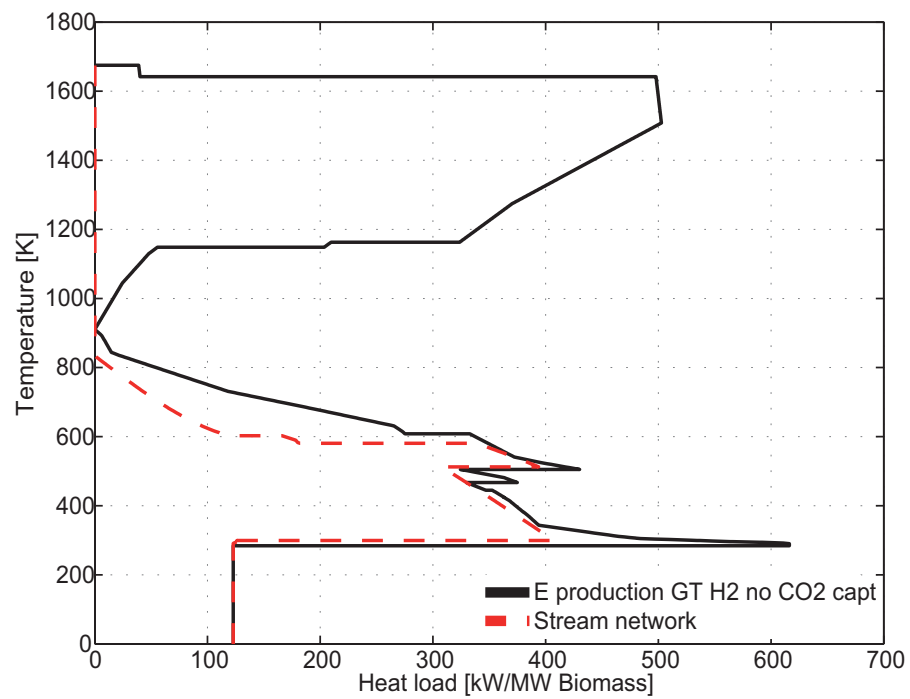

Figure 6: Integrated composite curve for the $\dot{E}$ production without $\mathrm{CO}_{2}$ capture and with steam network integration (config. G). 


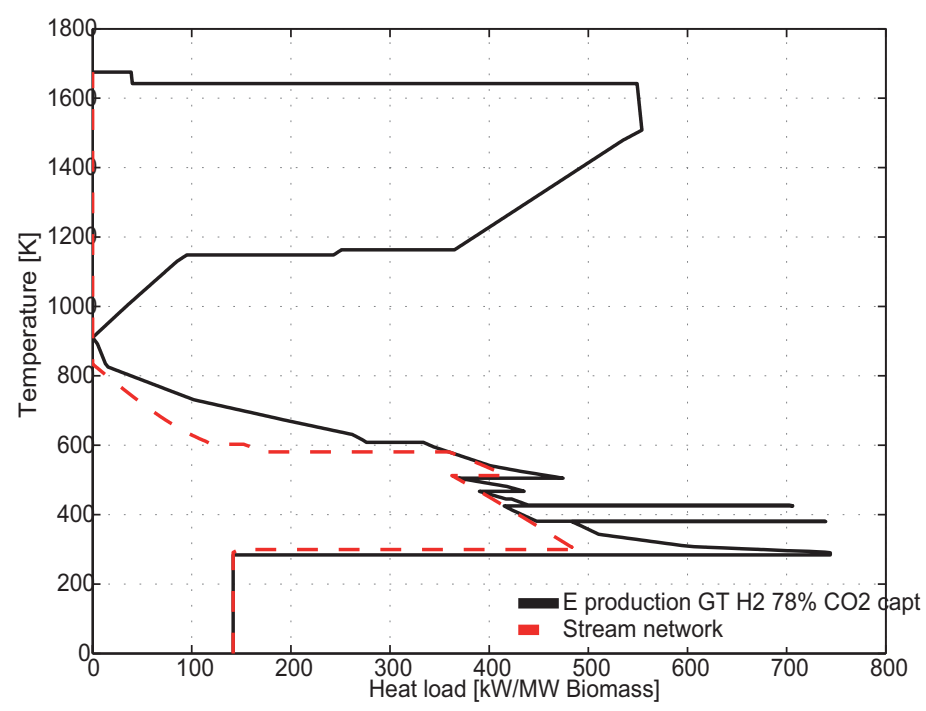

Figure 7: Integrated composite curve for the $\dot{E}$ production with $\mathrm{CO}_{2}$ capture and with steam network integration (config. H).

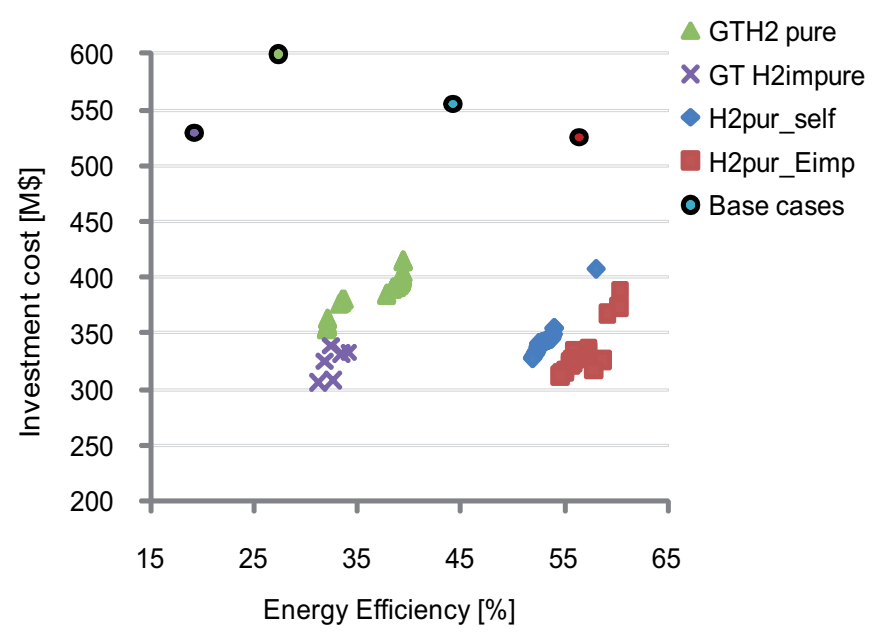

Figure 8: Optimal solutions in the Pareto domain for $\mathrm{H}_{2}$ processes (config. $\mathrm{C} \& \mathrm{D}$ ) and $\dot{E}$ generation processes (config. I\& $\mathrm{H}$ ) with regard to efficiency and investment. 


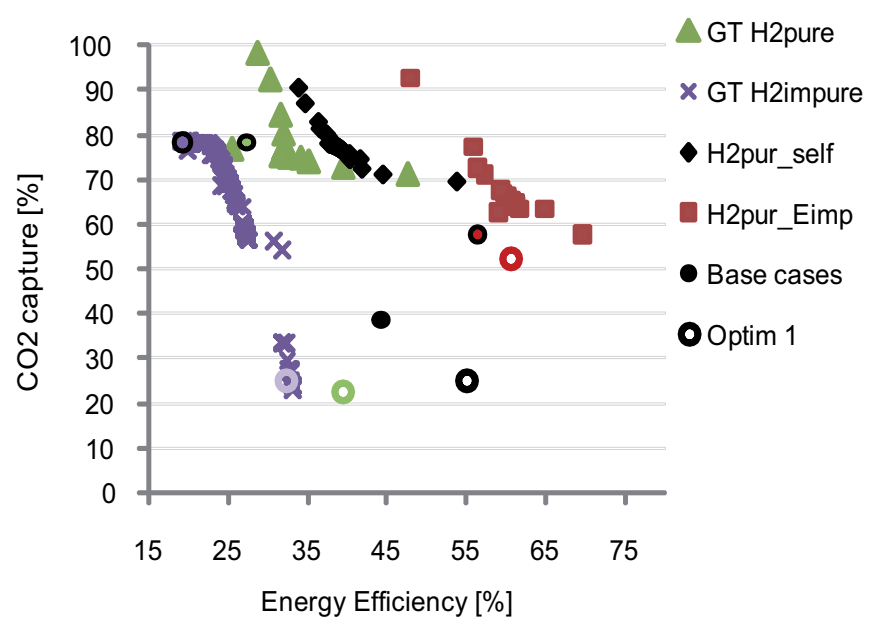

Figure 9: Optimal solutions in the Pareto domain for $\mathrm{H}_{2}$ processes (config. $\mathrm{C} \& \mathrm{D}$ ) and $\dot{E}$ generation processes (config. $\mathrm{I} \& \mathrm{H}$ ) with regard to efficiency and $\mathrm{CO}_{2}$ capture rate.

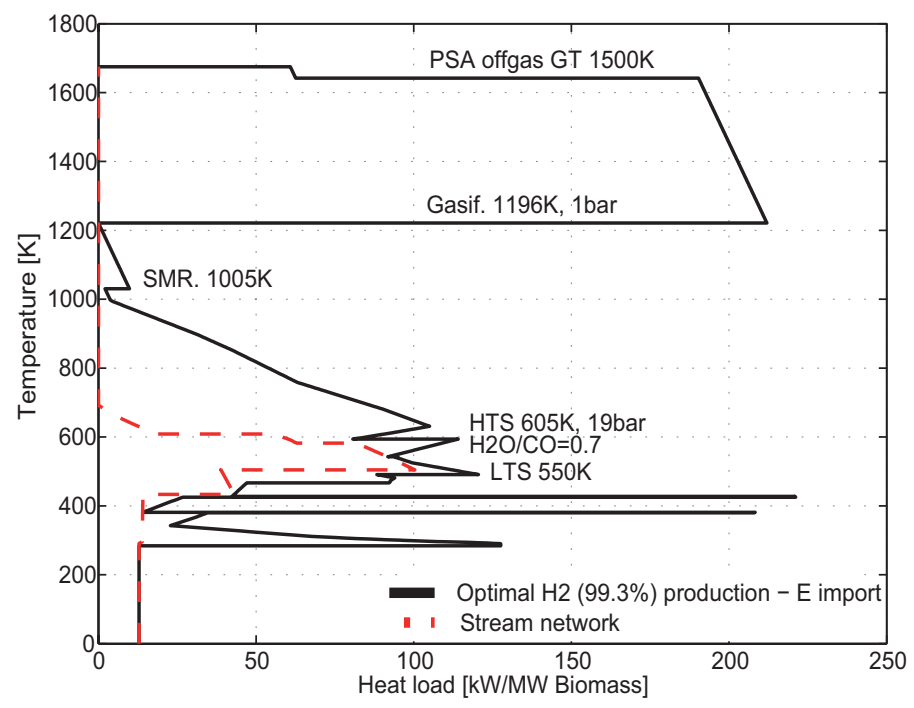

Figure 10: Integrated composite curve for an optimized $\mathrm{H}_{2}$ process with net $\dot{E}$ import and steam network integration (config. $\mathrm{C}_{\text {opt }}$ ). 


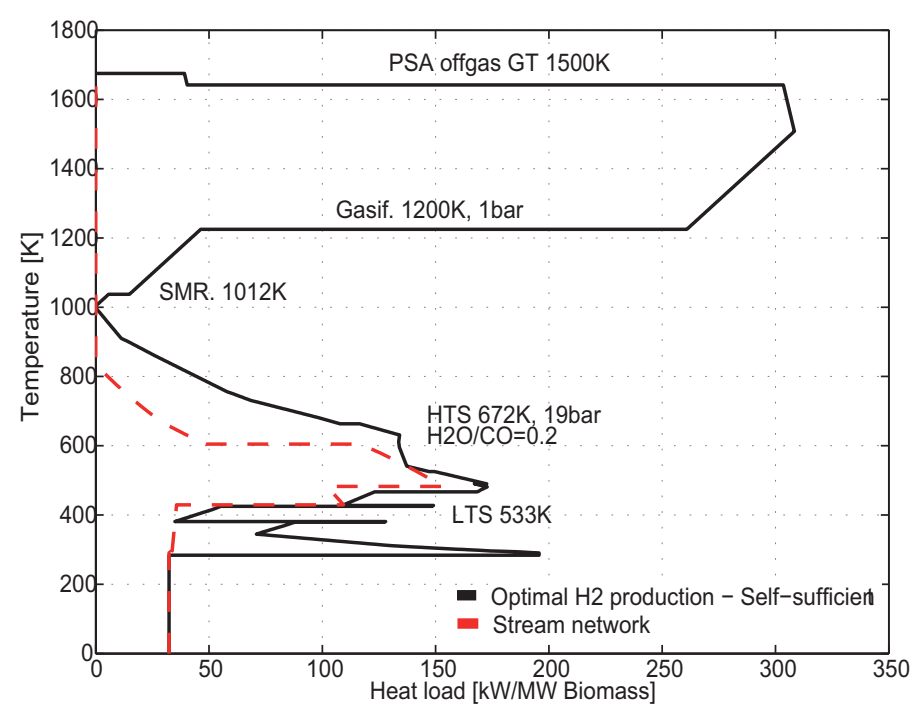

Figure 11: Integrated composite curve for an optimized self-sufficient $\mathrm{H}_{2}$ process with steam network integration (config. $\mathrm{D}_{\text {opt }}$ ).

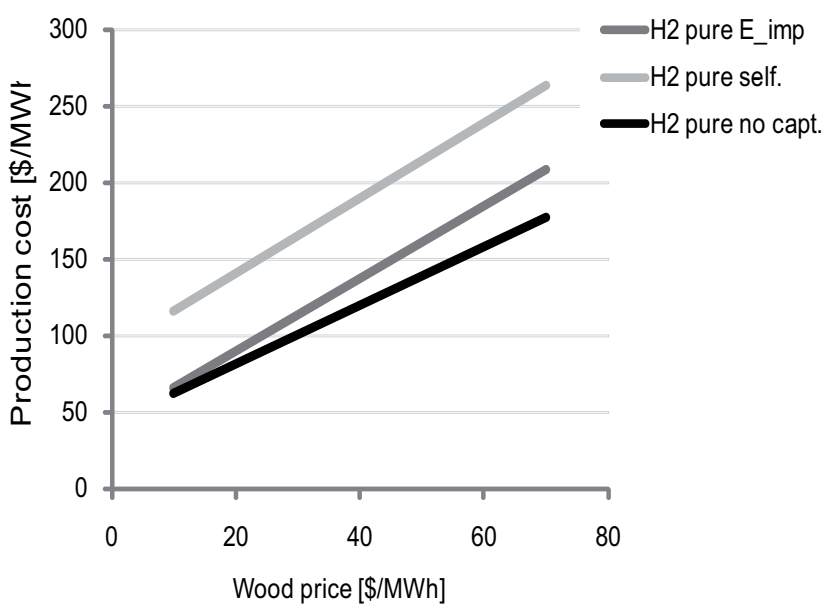

Figure 12: Sensitivity analysis of the wood cost on the hydrogen production cost $\left[\$ / \mathrm{MWh}_{H 2}\right]$ for different $\mathrm{H}_{2}$ scenarios (Table 7:B \& Table 8). 


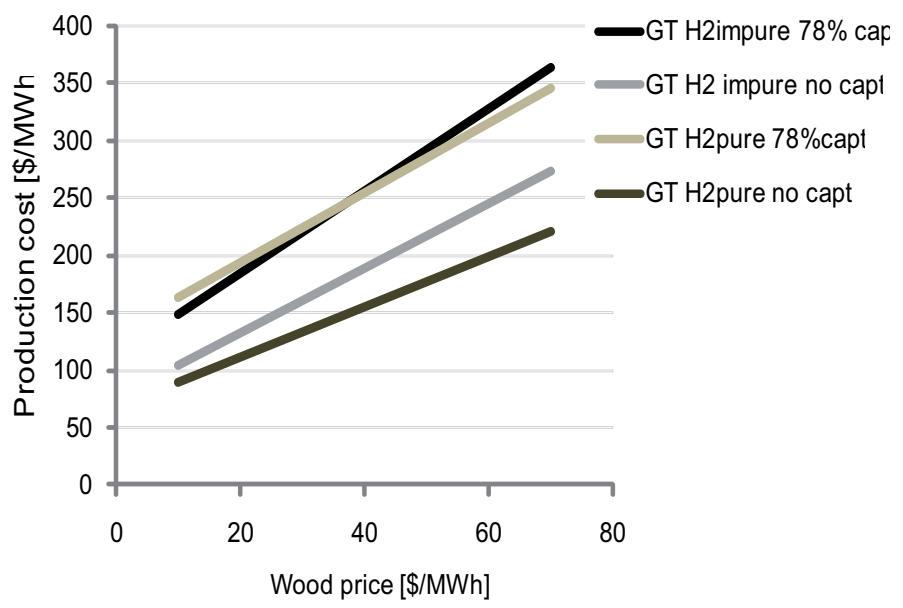

Figure 13: Sensitivity analysis of the wood cost on the electricity generation cost $\left[\$ / \mathrm{MWh}_{e}\right]$ for different scenarios (Table 7:G/I \& Table 8). 


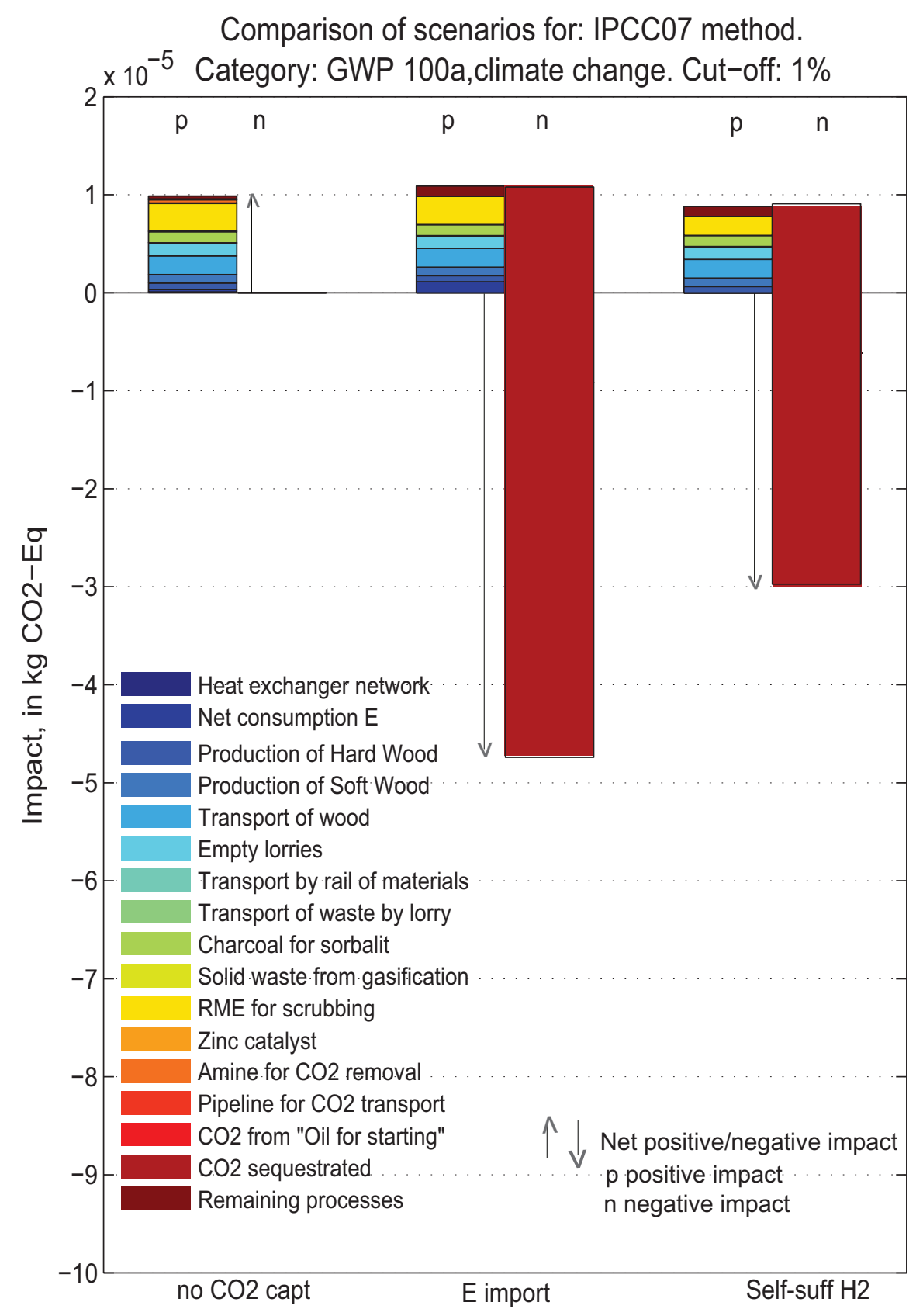

Figure 14: Comparison of the climate change impact of the $\mathrm{H}_{2}$ generation processes (Table 7:B/C/D) based on impact method IPCC07 for $1 \mathrm{~kJ}$ of biomass. 


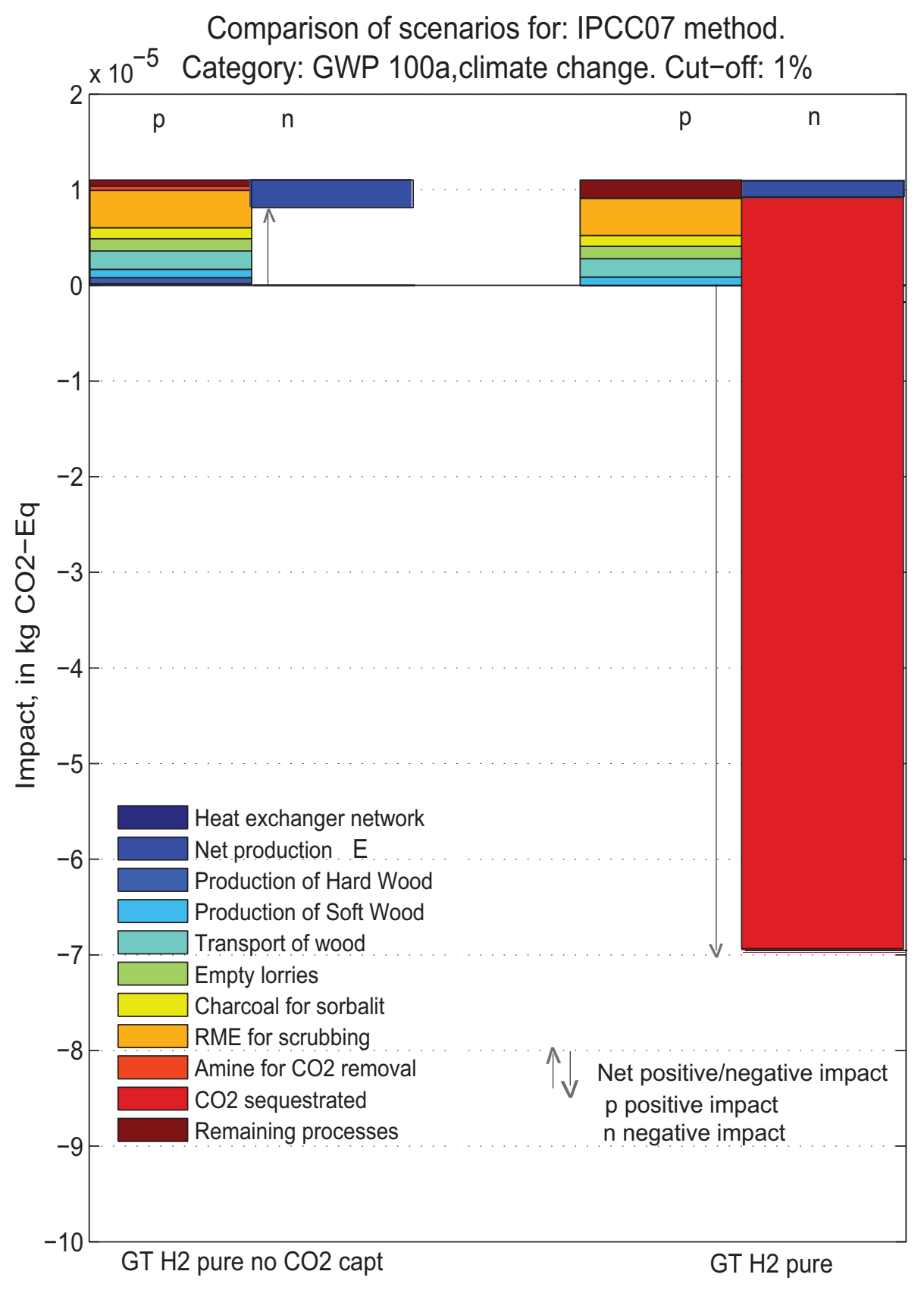

Figure 15: Comparison of the climate change impact of the electricity generation processes (Table 7:G-H) based on impact method IPCC07 for 1kJ of biomass. 